\title{
Wetness and Losses Control Using Geometry \\ Considerations in Low Pressure Stages of Steam Turbines
}

\author{
N. H. Mahmoud* and U. K. Singh** \\ * Minufiya University, Shebin El-Kom, Egypt \\ ** De Montfort University, Leicester, England
}

\begin{abstract}
This paper is concerned with investigating the effects of some geometrical characteristics of the cascade blades at low-pressure stages in steam turbines on the wet steam flow behaviour. The present work is based on a theoretical model combines a multistage three-dimensional semiviscous Euler solver with wet steam theory. Condensation of steam upon the surface of water droplets through the model is obtained on the basis of Lagrangian approach. Whilst the viscous effects in Euler solver are obtained using a body force treatment based on a simple mixing-length model. The blades geometrical characteristics is changed in the present study by cutting the blade at the trailing edge zone vertically and horizontally, or by profiling the blade end-wall. Present predictions show how the profiling of such a blade trailing edge and end wall are used separately or together to adjust and control both the flow behaviour and the situations of wetness accumulation. The present model predictions are in good agreement with the available experimental data.
\end{abstract}

\section{Nomenclature}

A flow cross-sectional area

B second virial coefficient

$C_{p} \quad$ isobaric specific heat capacity

E total internal energy

e specific internal energy

Manuscript received from Dr. N.H. MAHMOUD on : 30/ 12/1999

Accepted on : $6 / 3 / 2000$

Engineering Research Bulletin, Vol 23,No 2, 2000 Minufiya University, Faculty of Engineering, Shebien EI-Kom, Egypt, ISSN 1110-1180 


\begin{tabular}{ll}
$F_{v}$ & viscous force \\
$F_{v t}$ & tangential component of viscous force \\
$\mathrm{H}$ & total enthalpy \\
$\mathrm{h}$ & specific enthalpy \\
$\mathrm{I}$ & flow rothalpy \\
$\mathrm{J}$ & steady state rate of nucleation \\
$\mathrm{Kn}$ & Knudsen number \\
$\mathrm{k}$ & Boltzmann constant \\
$\mathrm{m}$ & mass of a molecule \\
$\mathrm{P}$ & pressure \\
$\mathrm{Pr}$ & Prandtl number \\
$q_{c}$ & condensation coefficient \\
$\mathrm{R}$ & gas constant \\
$\mathrm{r}$ & droplet radius \\
$r_{*}$ & critical radius of the nucleated droplet \\
$\mathrm{T}$ & temperature \\
$\mathrm{V}$ & velocity \\
$\bar{V}$ & velocity vector \\
$\mathrm{Y}$ & wetness fraction \\
$\gamma$ & ratio of specific heat capacities \\
$\Delta T$ & vapour subcooling \\
$\Delta v$ & volume of a grid unit \\
$\lambda$ & thermal conductivity \\
$\rho$ & density \\
$\sigma$ & surface tension \\
$\omega$ & rotational speed \\
$\mathrm{Subscripts}$ \\
$\mathrm{fg}$ & of phase transition \\
$\mathrm{g}$ & vapour phase \\
$\mathrm{l}$ & water phase \\
$\mathrm{S}$ & saturation conditions \\
& \\
\hline
\end{tabular}
Abbreviations
EW end-wall
HC horizontal cutting
HP high pressure
LE leading edge
TE trailing edge
VC vertical cutting

\section{Introduction}

When the steam experiences an expansion across nozzles or turbine blades, it supercools firstly and then nucleates to formulate a two-phase; wet 
steam mixture. Basically, this mixture contains a large number of minute water droplets with different sizes, which are suspended within the conveying vapour. Nucleation of these droplets and consequently its growth during wet steam expansion through turbine last stages or the so-called low pressure stages causes interphase temperature difference between the two phases of steam. This temperature difference creates an irreversible heat and mass transfer and therefore increases the so-called wetness loss [1]. Furthermore, wetness presence in the low pressure stages of steam turbines is considered the major reason of blading erosion and damage. In addition, when a wet steam flow is turned inside the blade passages; it becomes threedimensional one. It is of great importance to note that the three dimensional consideration involves the variation of flow angle along the span of the blade which is known as the secondary flow. Secondary flow leads to about half of the total losses in low pressure stages. Therefore, the correct prediction of this wetness and its accompanied thermal losses is considered the key to obtain a correct design when the best turbine performance is required.

Numerical methods of calculating the internal turbomachinery flow has always been the main tools of engineers and designers for a long time. This is because these methods can be used to zoom in situations where the turbomachinery designer has no previous knowledge about the flow behaviour that actually might occur. These methods started with $1 D$ approximations [2], and then developed to attain the 2D ones. In $2 \mathrm{D}$ approximations, the nucleation theory was coupled with Euler equations in order to simulate the wet steam flow through situations inside the low pressure turbines [3-5]. Recently, the $2 \mathrm{D}$ approximations were modified to avoid both extremely time-consumption and numerical stability problems using time-marching technique [6-7]. The first 3D complete solution for the flow inside turbomachinery was reported by Denton [8]. This pioneer work has been adopted by many investigators to achieve the recent inviscid 3D methods [9-11]. A fairly comprehensive presentation of the published time marching methods used in turbomachinery calculations can be found in the work of Singh [12]. Investigators effort were extended during the last two decades to introduce the viscous effects into the 3D methods. An extended review for these attempts in axial turbomachinery models was declared by Dawes[13]. Lastly, Singh [14] developed a model for a three-dimensional multistage treatment of nucleating and wet steam with the aid of Euler scheme. Singh's model includes the viscous body forces in order to enclose the effects of viscosity through Euler's solver.

Profiling turbine nozzles or blades was used by many investigators to control both the secondary losses and total losses inside steam turbines. The idea of blades or nozzles profiling is to influence the local pressure fields and consequently control the condensation through these situations. Diech, et al [15] published a pioneer work on investigating the effects of end-wall profiling in linear and annular cascades on the turbine losses. They reported 
that an increase in efficiency up to $1.5 \%$ was gained experimentally with profiled blades of aspect ratio of 0.5. Recently, Yan; et al [16] used the CFD code to investigate the effect of a profiled end-wall for a steam turbine HP nozzle guide vane on the pressure distributions upon the blade surfaces. They showed that the suggested profiling for the turbine nozzle row gives reductions of $6.6 \%$ of the total pressure loss and $14 \%$ of the secondary kinetic energy. In this respect, it is known that profiling TE zone affects greatly the flow behaviour downstream of such a cascade throats. This is because this profiling changes sharply the structure of vortices at the hub and tip corners.

In the present work a three-dimensional time marching method (Euler solver), allowing for including viscous forces is developed for predicting the behaviour of nucleating and wet steam flow through multistage turbines. The developed method is directed to investigate some design aspects for the end-wall and trailing edge profiles of cascade blades in the low pressure-last stages of steam turbines.

\section{Theoretical Model}

The theoretical model used here is based on three sets of equations which are used to simulate flow conservation, condensation and thermal behaviour. These sets are given below :

\section{Conservation Equations}

The basic system of equations for mass, momentum and energy conservation or the so-called unsteady Reynolds averaged Navier-Stokes equations in a fixed grid are given in Cartesian tensor form as :

$$
\begin{aligned}
& \frac{\partial \rho}{\partial t}+\nabla \cdot \rho \bar{V}=0 \\
& \frac{D \bar{V}}{D t}+\frac{\nabla P}{\rho}=F_{\theta} \\
& \frac{D e}{D t}+P \frac{D}{D t}\left(\frac{1}{\rho}\right)=F_{v t}
\end{aligned}
$$

where $\bar{V}=(\mathrm{u}, \mathrm{v}, \mathrm{w}), F_{v}$ is the viscous force and $F_{v t}$ is the tangential component of the viscous force. The above energy equation [i.e., equation (3)] can be released now in a more convenient form as:

$$
\frac{\partial \rho E}{\partial t}+\nabla \cdot \rho \bar{V} H=F_{v t}
$$


where $E$ and $H$ are the total energy and total enthalpy and can be defined as $E=e+V^{2} / 2$ and $H=h+V^{2} / 2$.

The evaluation of the magnitude and direction of the viscous force in equation (2) is determined by the local velocity and its derivatives using a simple mixing length model. In evaluating the viscous force, the normal direction is taken perpendicular to the blade surface only. This means that the direction of the surface shear stress is taken to be parallel to the surface velocity. The tangential component of the viscous force, $F_{v t}$, in equations (3-4) is calculated as shown previously by Denton [17]. An outline for the evaluation of both $F_{v}$ and $F_{v t}$ is given in Appendix (A).

\section{Condensation Equations}

The primary parameters in describing the condensation in such a media are the critical size of the droplets and nucleation rate. Here, the critical radius of nucleated droplets is calculated from Kelvin-Helmholtz formula as

$$
r_{*}=\frac{2 \sigma T_{s}}{\rho_{l} \cdot h_{f g} \cdot \Delta T}
$$

Whilst the nucleation rate is obtained per unit mass per second using the Lagrangian approach for the nucleation theory that was proposed by Kantrowitz [18] and adopted by Young [19] to become;

$$
J=q_{c} \sqrt{\frac{2 \sigma}{\pi m^{3}}} \frac{\rho_{g}^{2}}{\rho_{l}} \exp \left(\frac{-4 \pi r_{*}^{2} \sigma}{3 \mathrm{~K} T_{g}}\right)
$$

The process of droplet growth is described in the present work using a formula suggested by Young [19] to calculate the spontaneous condensation of steam at supersonic velocities by:

$$
\frac{d r}{d t}=\frac{\lambda\left(1-\frac{r_{*}}{r}\right)\left(T_{s}-T_{g}\right)}{h_{f g} \cdot \rho_{l} \cdot r\left[\left(\frac{1}{1+2 \beta K n}\right)+3.78(1-v) \frac{K n}{\operatorname{Pr}}\right]}
$$

where

$$
v=\frac{R T_{1}}{h_{f g}}\left[\alpha-0.5-\frac{2-q_{c}}{2 q_{c}} \cdot\left(\frac{\gamma+1}{\gamma}\right) \cdot \frac{C_{p} T_{s}}{h_{f g}}\right]
$$

The final parameter which gives a brief configuration for the condensation state is the wetness fraction and can be evaluated here using the following relation:

$$
Y=\frac{4}{3} \pi r^{3} \cdot N \cdot \rho_{l}
$$




\section{Thermal Behaviour Equations}

The thermal behaviour of such a fluid is defined basically with the aid of the equation of state and both the density and enthalpy. Hereinafter, the formulations used to simulate the wet steam thermal behaviour are presented.

The equation of state that has been used here to predict the properties of superheated and supercooled steam is of truncated virial form with temperature and density as independent variables. This equation is given as follows

$$
P=\rho_{g} R T_{g}\left(1+B \rho_{g}\right)
$$

where $\mathrm{B}$ is the second virial coefficient.

The present work utilizes the most recent correlation for this coefficient that reported by Young [19].

Now, wet steam density can be written in terms of $\mathrm{Y}$ as

$\rho=\frac{\rho_{g}}{1-Y}$

Finally, wet steam enthalpy can be calculated from

$$
h=(1-Y) \cdot h_{g}+Y \cdot h_{l}
$$

\section{Numerical Treatment}

When solving the Euler's conservation equations (1-4) in a rotating blade row, it has been found that it is more convenient to work with a fixed grid which instantaneously coincides with the rotating one. Applying equations (1-4) on a fixed grid of $\Delta v$ volume within a two-phase flow of wet steam in a time interval $\Delta t$ gives the following:

$$
\begin{gathered}
\Delta \rho=\frac{\Delta t}{\Delta v} \sum\left[\rho V_{x} d A_{x}+\rho V_{\theta} d A_{\theta}+\rho V_{r} d A_{r}\right]+\omega \cdot \frac{\partial \rho}{\partial \theta} \cdot \Delta t \\
\begin{array}{r}
\Delta\left(\rho V_{x}\right)=\frac{\Delta t}{\Delta v} \sum\left[\left(P+\rho V_{x}^{2}\right) \cdot d A_{x}+\rho V_{x} V_{r} . d A_{r}+\rho V_{x} V_{\theta} \cdot d A_{\theta}\right] \\
+\omega \cdot \frac{\partial\left(\rho V_{x}\right)}{\partial \theta} \cdot \Delta t
\end{array}
\end{gathered}
$$




$$
\begin{array}{r}
\begin{array}{r}
\Delta\left(\rho V_{r}\right)=\frac{\Delta t}{\Delta v} \sum\left[\rho V_{x} V_{r} \cdot d A_{x}+\rho V_{\theta} V_{x} \cdot d A_{\theta}+\left(P+\rho V_{r}^{2}\right) \cdot d A_{r}\right] \\
+\left[\rho \frac{V_{\theta}^{2}}{r} \cdot \omega \cdot \frac{\partial\left(\rho V_{r}\right)}{\partial \theta}\right] \cdot \Delta t
\end{array} \\
\begin{array}{r}
\Delta\left(\rho V_{\theta}\right)=\frac{\Delta t}{\Delta v} \sum\left[\rho V_{x} \cdot r V_{\theta} \cdot d A_{x}+\rho V_{r} \cdot r V_{\theta} \cdot d A_{r}+\left(P+\rho V_{\theta}^{2}\right) r d A_{\theta}\right] \\
+\omega \cdot \frac{\partial\left(\rho r V_{\theta}\right)}{\partial \theta} \cdot \Delta t
\end{array} \\
\begin{aligned}
\Delta(\rho E)=\frac{\Delta t}{\Delta v} \sum\left[\rho V_{x} H \cdot d A_{x}+\rho V_{r} H \cdot d A_{r}\right. & \left.+\rho V_{\theta} H \cdot d A_{\theta}\right]+\omega \cdot \frac{\partial(\rho E)}{\partial \theta} \cdot \Delta t
\end{aligned}
\end{array}
$$

The numerical scheme which is used in solving equations (12-14) is based on a modified time marching method proposed by Denton [20]. However, depending on the flow conditions the following steps are taken : Firstly, the grid system used here is illustrated in Fig. (1). The quality of grid plotting is not good due to the resolution of the computing system. In the blade to blade system, this system is formed by a series of unevenly placed quasi-streamlines, which are intersected by unevenly spaced pitchwise lines at constant values of axial position. The grid used in this work is of a size of $(212 \times 41 \times 21)$. In such 3D grid system, it is of great importance to note that the projected areas of all 6 faces of each grid element must be closed and the following constraint should be achieved

$$
\sum d A_{x}=\sum d A_{\theta}=\sum d A_{r}=0
$$

Now, solution is started with equation (12) in order to get new values of density. Equation (14) is then solved for new values of $\rho E$. Using these new values of $\rho E$, one can be able to obtain new values for the pressure.

Numerical solution can be divided into dry solution and nucleating or wet one. It is essential to start the calculations from the case of dry solution where the steam enters the blades row in the superheated state and then goes within the blades and leaves it as dry steam. This is necessary for numerical stability and also to achieve savings in the required time for wet computations. Furthermore, results of dry calculations for the tested row of blades are required to start the case of wet calculations. In dry calculations, where $\rho=\rho_{g}$, the obtained temperature (T) from equation (14) must match with $T_{g}$ at each grid point. If this is not achieved, the value of $T$ must be driven slowly towards $T_{g}$ through iterations progress with the aid of a user specified relaxation factor.

In wet calculations, the beginning and end of nucleation zone are obtained with the aid of equation (7) considering the minimum values of the 
nucleation rate. Equation (8) is then integrated to calculate the droplet growth on streamline basis. The wetness fraction can be obtained from equation (9). Whilst equations (10) and (11) are then used for consistency. Equations (13.a,b\&c) which represent the momentum conservation in three directions are solved to update the three components of the flow velocity. These velocity components are then fed back to update values of density in equation (12) to commence a new iteration cycle.

The computations of the present study were carried out using a UNIX operator of the SUN machine at the Faculty of Computing Sciences and Engineering in De Montfort University.

\section{Results and discussion}

First of all, the tested blade profiles used in the present work are given in Fig. (2). In the first configuration, i.e. profiling TE zone, the basic profile of the blade used here is that suggested previously by Bakhtar and others [21] as shown in Fig. (2.a-i). Profiling TE zone in the present investigation is carried out by cutting the blade in this zone horizontally and vertically as also illustrated in Figs. (2.a-ii\&iii). A new concept for the blade EW profiling has been developed and given in Fig. (2.b). This concept is simply based on reducing the blade EW in four steps namely (1-2), (2-3), (3-4) and (4-5). The step (1-2) is a straight line have the basic blade height, the step (2-3) is a concave arc, the step (3-4) is a convex arc whilst the last step (4-5) is a straight line extends to TE plane. The four steps of blade EW profiling can reduce the blade height at TE by $15 \%$ of the original one at LE. It is of great importance to note that all the theoretical results presented below are from calculations were carried out at the blade mid height.

Figure (3) illustrates a sample of the present model predictions for the variations of nucleating steam characteristics during such an expansion through a row of two blades with the basic profile in Fig. (2.a-i) \{ i.e. profile of Bakhtar, et al [21]\}. Plots of Fig. (3) include both the aerodynamic and velocity characteristics for the investigated wet steam flow. The boundary conditions of the results of Fig. (3) are; steam stagnation pressure ahead of cascade entrance is $0.999 \mathrm{bar}$, amount of subcooling equals $-11.9 \mathrm{~K}$ and an overall inlet total to back static pressure ratio of 2.34 . The aerodynamic characteristics presented in Fig. (3.a) involve surface distributions for both the static pressure and Mach number upon the blade surfaces besides contours for both the static temperature and wetness fraction. Also shown in Fig. (3.b) the predicted velocity characteristics of the tested nucleating steam flow. The velocity characteristics in Fig. (3.b) contain contours for the flow mean velocity and its three components (i.e.; axial, tangential and radial ones). The trends and levels of the surface distributions for both the static pressure and Mach number in Fig. (3.a) displayed qualitative agreement with the reported experimental results using such measurement facilities as pressure measurements [21,22]. However, patterns of such other plots in Fig. (3), e.g. contours of the velocity and wetness fraction, are similar to those obtained previously from quasi-3D [23] and 3D theoretical 
models [14,20]. Another samples of present model predictions for the basic blade of Bakhtar, et.al. [21] profile and with HC and VC at TE zone are presented in Figs. (4\&5). These figures involve surface distributions upon the blade for both the static pressure and Mach number, as well as contours for the static temperature and Mach number.

A comparison is given in Fig. (6) between the predicted static pressure distributions upon the blade surfaces and Mach number contours for dry and nucleating steam flow through cascade blades with the basic profile of Bakhtar, et al [21]. The boundary conditions for the dry steam calculations are taken here similar to those used previously in the experiments of Bakhtar, et al [21]. These conditions are as follows: stagnation pressure before the cascade equals 0.997 bar, amount of superheating can be taken as $46.6 \mathrm{~K}$ and the overall inlet total to back static pressure ratio is 2.36 . Generally speaking, it will be seen that the pressure distributions upon the blade surfaces in Fig. (6.a) are almost identical in the general behaviour. It will be noticed in the pressure distributions of Fig. (6.a) the two zones of pressure discontinuities upon the blade surfaces and near to the TE. In the first zone an abrupt pressure increașe occurs on the pressure surface and in the second one an overexpansion bubble lies nearst to the $\mathrm{LE}$ and on the suction surface. These zones were reported by the theoretical work of many investigators [14,24] and by the experimental results of Bakhtar and Mahpeykar [24] using the Mach Zehnder technique. The pressure distribution on the suction surface shows the occurrence of an oblique aerodynamic shock at about $44 \%$ fraction of axial blade chord. This shock was observed during the experimental measurements of Bakhtar, et al [21] at about more than $40 \%$ of the axial blade chord. This clear coincidence between the present predictions and previous measurements confirms the suggested model of the present work. As concluded by Snoeck [25], the heat release due to condensation causes the static pressure upon the blade suction surface to be increased above the corresponding values of the dry steam flow. The static pressure distributions upon the blade pressure surface in Fig. (6.a) show approximately similar trends and values. This observation was obtained experimentally and reported by Snoeck [25]. The reason for this tendency was, as explained by Snoeck [25], that with changing the upstream steam temperature the volume flow rate is not greatly changed. The remainder plots in Fig. (6), i.e. Fig. (6.b), are for the condensation effect on the predicted Mach number contours. In this figure, it can be noticed that the Mach number contours are approximately similar upstream of the sonic Mach number contour or the throat section. While there are a notable difference downstream this contour of $M=1$ especially towards the pressure surface. A reasonable explanation for this behaviour is that the condensation zone starts from the throat section and extends in the downstream direction. Therefore, due to the heat liberation across this zone the steam temperature and consequently its density and velocity besides the frozen speed of sound must differ from the other ones with the dry steam flow through the blades. 
Effect of TE zone profiling on the predicted contours of the static pressure and wetness fraction is shown in Fig. (7). Evidence of TE shock waves has been observed clearly in the plot of static pressure contours with the basic profile of Bakhtar, et al [21]. This evidence is much clear when the TE zone profiled with both HC and VC. Shock waves appeared in the plot that was taken using the basic blade profile and shown in Fig. (7.a) include two types; namely passage and reattachment shocks. At the TE zone, it is easy to see the appeared weak reattachment shock at the right side of the strong pressure one which extends across the flow passage towards the suction surface of the next blade in the cascade. Blade HC causes to damp the reattachment shock at the TE zone and slightly increases the intensity of the pressure one. This is because the cutted section from the blade changes the throat area between TE of such a blade and the opposite suction surface of the next blade in the cascade. This area variation at the throat makes the passage shock be stronger. In addition, the removed section from the surface of TE zone vanishes completely the reattachment conditions. This system of shock waves was appeared and discussed previously in the predictions of Singh [26] and Young [19]. However; in the case of blade VC, where sharp change in TE geometry occurs, it is clear that the passage shock becomes stronger than the similar ones of other profiles. Furthermore, blade VC blots out also the reattachment shock. This tendency is due to the sharp nose of the blade that disrupts the flow homogenity. The latter plots in Fig. (7) include the effect of TE zone profiling on the predicted wetness contours. The mean features of this plot coincide completely with the published predictions of Singh [14]. These features involve the occurrence of two condensation zones. The first, or the biggest one appears and occupies the whole of flow passage and begins after about $25 \%$ of the suction surface length. The reason for this higher wetness accumulation is due to the socalled "Wilson zone" which generally lies beyond the throat section. Measurements of blade wetness and subcooling distributions in [25] can justfy this discussion. The second condensation zone extends upon the suction surface and in the downstream direction as an extension for this surface. Blade $\mathrm{HC}$ causes a slight increase in both condensation zones. Whilst blade $\mathrm{VC}$ results in different behaviour for the wetness contours. It is evident that $\mathrm{VC}$ divided the first condensation zone in the middle of flow passage into two sections and moves the second zone in the upstream direction upon the suction surface. Furthermore, it can be seen that the blade VC affects also the behaviour of wetness contours downstream of the cascade.

Figures (8) through (10) illustrate the effects of EW profiling on some of the predicted characteristics of nucleating steam flow inside cascades with three different profiles of the blade trailing edge zone. These profiles are presented schematically in Fig. (2). The effect of EW profiling for the cascade blades of Bakhtar, et al [21] profile on the tested flow characteristics is released in Fig. (8). Firstly, the effect of EW profiling on the flow aerodynamic characteristics is given in Fig. (8.i). Here, contours of both Mach number and wetness fraction are used to declare the effect of EW 
profiling. The main feature of the comparison in these plots is that the two flow behaviours are approximately similar. Secondly, the effect of EW profiling on the flow velocity characteristics is shown in Fig. (8.ii). Although EW profiling decreases slightly the magnitude of the velocity upon the blade surfaces as shown in Fig. (8.c), its behaviour is still unchanged except through the first $5 \%$ of the pressure surface length. Whilst EW profiling show a clear effect on the distributions of the radial velocity components on the blade surfaces as shown in Fig. (8.d). Investigation of the predicted surface distributions for the other velocity components for the two cases of comparison in Fig. (8), which are not enclosed here, declares a slight variation with EW profiling. This is the reason for the constancy of the predicted characteristics in Fig. (8).

Figure (9) illustrates the predicted effects of EW profiling for the cascade blades of Bakhtar, et al [21] profile and with $\mathrm{HC}$ at the trailling edge. In order to declare these effects, a comparison between the predicted contours of both Mach number and wetness fraction as well as surface distributions for both the flow mean velocity and its radial component upon the blade surfaces have been presented here. A different behaviour for Mach number contours upstream the throat plane is clearly being seen in Fig. (9.a). It can be seen that the contour of $(M=0.3)$ transfers downstream in the flow passage with blade EW profiling. In addition, it can be noticed that EW profiling affects also the characteristics of Mach number contours downstream of the throat section. This effect appeared clearly in moving the incidence location of the sonic contour $(M=1)$ downstream upon the blade suction surface as shown in Fig. (9.a). The reason for this tendency is that, EW profiling reduces the velocity in the region of highest turning and creates excessive acceleration for the flow in the downstream direction of the blade passage. The explanation of this tendency has come from Fig. (9.c). Distributions of the mean velocity in this figure indicate that $\mathrm{EW}$ profiling for the blade of basic profile decreases the local values of the velocity on both the blade surfaces and changes noticeably the velocity behaviour within the last $10 \%$ of blade axial chord. Reduction of the average velocity and consequently some of its components results in a need for more time/distance within the flow passage to achieve the corresponding velocity for the sonic Mach number. Investigating the complete velocity characteristics can support this explanation. Plots of all velocity components for the tested profiles which are not included in Fig. (9) show that EW profiling for Bakhtar, et al [21] blade with $\mathrm{HC}$ reduces clearly all the velocity components and also changes the behaviour of both axial and tangential components through the last $10 \%$ of blade axial chord. The major effect of EW profiling can happen with the radial velocity distributions as shown in Fig. (9.d). Complete damping of the radial component along the blade with $\mathrm{HC}$ at trailing edge occurs with EW profiling. This damping adjusts the velocity field upon the blade surfaces especially in the trailing edge zone. Changing the aerodynamic characteristics of steam flow inside the blade passage due to $\mathrm{EW}$ profiling have an impact also on the condensation behaviour as illustrated in Fig. (9.b). From this plot it can be 
concluded that, reducing the secondary flow upon the blade suction surface with EW profiling results in moving the thin condensate layer on this surface in the downstream direction.

The effects of combining both $\mathrm{VC}$ and $\mathrm{EW}$ are discussed by examining the plots of Fig. (10). This figure contains plots for the surface distributions of the static pressure, Mach number and radial velocity component as well as contours of the wetness fraction. End wall profiling for the blades with VC causes to decrease the static pressure upon the suction surface from LE to about more than $60 \%$ of the blade axial chord and furthermore cause to increase the rate of pressure drop ahead of the condensation shock location at about $50 \%$ of chord length. However, EW profiling rises the static pressure along the last half of chord length on the pressure surface as shown in Fig. (10.a). Analysing Fig. (10.b) indicates that the static pressure variation on the blade surfaces can reflect in lowering the velocity and consequently Mach number values along the first $60 \%$ of suction surface length and within the last $10 \%$ of the suction surface length. The reason for all tendencies of plots in Figs. (10.a) and (10.b) is the adjustment that can happen for the radial velocity component in Fig. (10.c) with EW profiling. Here, EW profiling damps clearly the inverse flow especially on the suction surface. Finally, the predicted wetness contours declare that EW profiling affects significantly the behaviour of condensate accumulation. Due to EW profiling of the basic blade with VC at TE the condensate layer along the suction surface was vanished and directed to increase the condensate intensity about the wake of passage shock and of the mean fog across the flow core.

Finally, a comparison between the predicted pressure distributions around the blade surfaces and the reported experimental data of Bakhtar, et al [21] for nucleating steam flow through cascade blades of basic profile has been presented in Fig. (11). As can be seen, the agreement on the pressure surface side is quite good. Besides, on the blade suction surface, both theoretical predictions and measurements reveal the occurence of a shock wave at about $44 \%$ of axial chord downstream of LE. It is also noticed that the measured shock is stronger than the predicted one. The reason for this difference is due to the presence of a lambda shock accompanying the fog condensation in this side.

\section{Conclusions}

The work presented here has described a three-dimensional two phase approach for predicting the steady state flow characteristics of low pressure steam turbines. The present model is utilized to investigate some aspects of blading design philosophy. Flow predictions from the present model give a pronounced explanation for both the engineer and designer about what may happen in all the turbine stages. Theoretical results obtained here show a significant effect of changing the blade profile on both the aerodynamic and condensation characteristics of the steam flow through cascade blades of low pressure turbine stages. For example, the predictions 
presented here demonstrate that the TE profiling affects clearly the system of aerodynamic shocks inside the cascade passage, whilst the EW profiling changes greatly the location of wetness accumulation through the cascade. Finally, a comparison between the present predictions and the available experimental data has also been carried out. Quite good agreement is obtained and it can be stated that the predictions have managed to capture the flow characteristics extremely well.

\section{Acknowledgment}

The authors are most grateful to Dr. Hassan Abdalla and the Concurrent Engineering group at the Faculty of Computing Sciences \& Engineering in DeMontfort University at Leicester for their valuable assistance during the computations of this work. The authors also thank Mr. Abdel Moneim Ahmed, Research Doctorate student for his assistance during the preparation of this manuscript.

\section{References}

1. Young, J.B.,"Non-equilibrium wet steam flow in low pressure turbines", Lecture in Chapter (4) in: "Aerotherodynamics of low pressure steam turbines and condensers", Edited by : Moore, M. J. and Sieverding, C. H., Hemisphere Publ., Washington, pp. 87-113, 1987.

2. Yeoh, C. C. and Young, J. B.,"Nonequilibrium streamline curvature throughflow calculations in wet steam turbines", Trans. ASME, J. of Engng for Power, Vol. 104, pp. 489-496, 1982.

3. Bakhtar, F., Mahpeykar, M. R. and Abbas, K. K., "An investigation of nucleating flows of steam in a cascade of turbine blading - Theoretical treatment”, Trans. ASME, J. Fluids Eng., Vol. 117, pp. 138-144, 1995.

4. Singh, G., Hunt, R. and McCallum, M.,"Wet steam analysis using Eulerian method for two-dimensional droplet growth and nucleation rate equations", Inst. Mech. Eng., paper C557/099/99, pp. 783-801, 1999.

5. White, A. J., Young, J. B. and Walters, P. T., "Experimental validation of condensing flow theory for a stationary cascade of steam turbine blades", Phil. Trans. Roy. Soc. Lond., Sers.A, Vol. 354, pp. 59-88, 1996.

6. White, A. J. and Young, J. B., "Time-marching method for the prediction of two-dimensional, unsteady flows of condensing steam", AIAA, J. of Propulsion and Power, Vol. 9, No. 4, pp. 579-587, 1993. 
7. Chmielniak, T., Wroblewski, W. and Dykas, S., "Steam flow calculations in turbine channels", Inst. Mech. Engrs., paper C557/123/99, pp. 803$813,1999$.

8. Denton, J. D., “A time-marching method for two and three dimensional blade to blade flow", ARC R\&M 3775, 1975.

9. Thompkins, W. T., "An experimental and computational study of flow in a transonic compressor rotor", Ph. D. Thesis, M. I. T., 1976.

10.Bosman, C. and Highton, J., "A calculation procedure for 3D timedependent inviscid, compressible flow through turbomachinery blades of any geometry", J. of Mech. Engng Science, Vol. 21, No. 1, 1979.

11.Enselme, M., Brochet, J. and Boisseau, J. P., "Low cost 3D flow computations using a mini-system", AIAA J., Vol. 20, No. 11, pp. 15151520,1982 .

12.Singh, U. K., "Time marching methods for turbomachinery flow calculation", Lecture series on turbomachinery design \& analysis methods, Cranfield Institute of Technology, UK, June 1987.

13.Dawes, W. N.,"Developments in the calculation of $3 \mathrm{D}$ viscous compressible flow in axial turbomachinery", Lecture in Chapter (3) from : "Aeorotherodynamics of low pressure steam turbines and condensers", Edited by: Moore, M. J. and Sieverding, C. H., Hemisphere Publ., Washington, pp. 73-85, 1987.

14.Singh, U., "Method for nucleating steam flow in low-pressure turbine stages", Inst. Mech. Engrs., paper C557/010/99, pp. 827-836, London, 1999.

15.Deich, M. E., Zaryankin, A. E., et al, "Method of increasing the efficiency of turbine stages", Teploenergetica, Vol. 2, pp. 18-24, in Russian, 1960.

16.Yan, J., Gregory-Smith, D. G. and Ince, N. Z., "Profiled end-wall design for a turbine nozzle row", Inst. Mech. Engrs., paper C557/060/99, pp. 453-464, London, 1999.

17. Denton, J. D., "The use of distributed body force to simulate viscous effects in 3D flow calculations", ASME paper 86-GT-144, 1984 .

18.Kantrowiz, A. "Nucleation in Very Rapid Expansions", Journal of Chemical Physics, Vol. 19, No: 9, pp.1097-1100, 1951.

19.Young, J. B., "Wet steam flows", Cambridge University lecture series on turbomachinery, 1994.

20.Denton, J. D., "The calculation of fully three dimensional flow through any type of turbomachine blade row", AGARD-LS-140, pp. 9.1-9.20, 1985.

21.Bakhtar, F., Ebrahimi, M. and Webb, R. A., "On the performance of a cascade of turbine rotor tip section blading in nucleating steam - Part 1 : surface pressure distributions", Proc. Instn Mech. Engrs, Vol. 209, Part C, pp.115-123, 1995.

22.Denton, J. D., "Calculation of the $3 \mathrm{D}$ inviscid flow through a turbine blade row", Lecture in Chapter (3) from: "Aeorothermodynamics of low pressure steam turbines and condensers", Edited by : Moore, M. J. and Sieverding, C. H., Hemisphere Publ., Washington, pp.57-73, 1987. 
23.Young, J. B., "Two-dimensional, nonequilibrium, wet-steam calculations for nozzles and turbine cascades", Trans. ASME, J. Turbomachinery, Vol. 114, pp. 569-579, 1992.

24.Sieverding, C. H., "Aeorodynamic characteristics of last stage blade profiles", Lecture in chapter (5) from : "Aeoro-thermodynamics of low pressure steam turbines and condensers", Edited by : Moore, M. J. and Sieverding, C. H., Hemisphere Publ., Washington, pp.144-163, 1987.

25. Snoeck, J., "Two dimensional condensing flow in transonic turbine cascades", Lecture in chapter (4) from: "Aeorothermodynamics of low pressure steam turbines and condensers", Edited by : Moore, M. J. and Sieverding, C. H., Hemisphere Publ., Washington, pp. 113-129, 1987.

26.Singh, U. K., "Computation of transonic flows in and about turbine cascades with viscous effects", ASME paper number 84-GT-18, 1984.

\section{Appendix (A)}

\section{Simulation of viscous effects}

The approach used in the present investigation for the inclusion of viscous effects into the 3D Navier-Stokes solver utilizes the suggestions of both Denton [20] and Singh [14]. This approach is based on introducing the viscous force terms into the momentum equations and both terms of shear work and heat flow in the energy equation. Therefore, the following must be followed to achieve this purpose.

Introducing a viscous force term in the differential form of the momentum equation in the direction of the streamlines through the fixed control volume in Fig. (12) gives

$$
\rho V \cdot \frac{\partial V}{\partial s}=-\frac{\partial P}{\partial s}+\frac{\partial \tau}{\partial n}
$$

where $s$ refers to the streamline surface and $n$ denotes the normal direction upon the streamline surface.

Referring to Fig. (12) also, the energy conservation along the streamline considering the shear work and heat flow terms takes the following form

$$
\rho V \frac{\partial H}{\partial s}=\frac{\partial(\tau V)}{\partial n}-\frac{\partial q}{\partial n}
$$

where $\tau V$ represents the shear work done by the viscous shear stress and $q$ means the heat flow in a direction normal to the streamline. Considering both Newton's law of viscosity and Fourier's law of heat conduction to substituting $\tau$ by $\{\mu(\partial V / \partial n)\}$ and $\mathrm{q}$ by $\{-\lambda(\partial T / \partial n)\}$ yields to give equation (A-2) the following form

$$
\rho V \frac{\partial H}{\partial s}=\frac{\partial}{\partial n}\left(\mu V \frac{\partial V}{\partial n}+\lambda \frac{\partial T}{\partial n}\right)
$$


After a little algebra, the last equation becomes

$\rho V \cdot \frac{\partial H}{\partial s}=\frac{\mu}{\operatorname{Pr}} \cdot \frac{\partial^{2}}{\partial n^{2}}\left[H+(\operatorname{Pr}-1) \cdot \frac{V^{2}}{2}\right]$

It is known that Prandtl number (Pr) can be taken equal unity in all laminar and turbulent flow situations. Considering this assumption can reduce equation (A-4) to become

$\rho V \cdot \frac{\partial H}{\partial s}=\mu \cdot \frac{\partial^{2} H}{\partial n^{2}}$

If $\mathrm{H}$ of the inlet flow is uniform and the flow is adiabatic, then $(\mathrm{H}=$ constant $)$ is considered a good approximation for the solution of the energy equation [ i.e., equation. (A-5)]. This means that the energy equation used for the Euler equations may be applied unchanged to the Navier-Stokes equations. Applying this criterion on the rotating coordinate system leads to that the flow rothalpy, $\mathrm{I}=\mathrm{H}-\omega r V_{\theta}$, is unchanged also by the viscous effects. The constant rothalpy conditions means that

$\frac{\partial}{\partial s}(m I)=0$

and the moment of momentum equation along the relative streamline is

$\frac{\partial}{\partial s}\left(\dot{m} r V_{\theta}\right)=r F_{\theta}$

where $F_{\theta}$ is the total tangential force acting on the fluid element including both the pressure force and the tangential component of the viscous force.

Combining equations (A-6) and (A-7) releases the rate of change of stagnation enthalpy along the stream line as

$m \cdot \frac{\partial H}{\partial s}=r F_{\theta}$

To implement the above model in the present Euler solver, it is only necessary to obtain the three components of the viscous force acting on each finite volume and to include the force as a source term in the right hand side of each of the three momentum equations [i.e., equations (13.a,b\&c)]. However, the tangential component of the force multiplied by the local rotational speed $\omega$ must be inserted into the right hand side of the energy equation [ i.e., equation (14)]. Finally, the present work estimates the surface shear stress with a reasonable accuracy using a simple Prandtl mixing length model. 


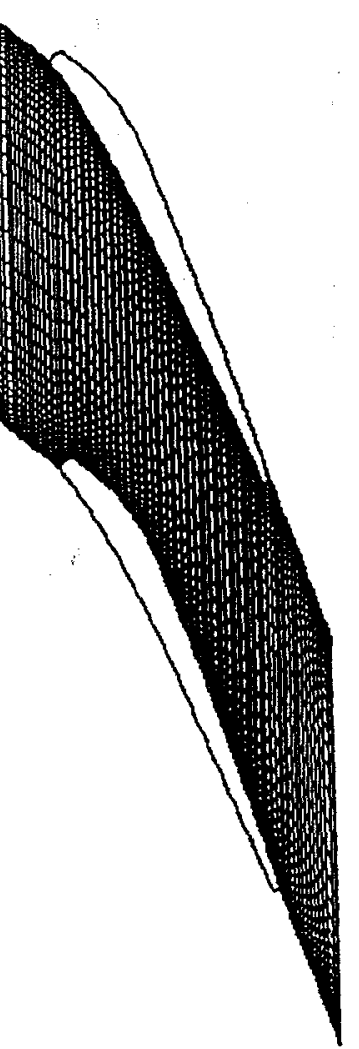

Figure (1) : Computational mesh
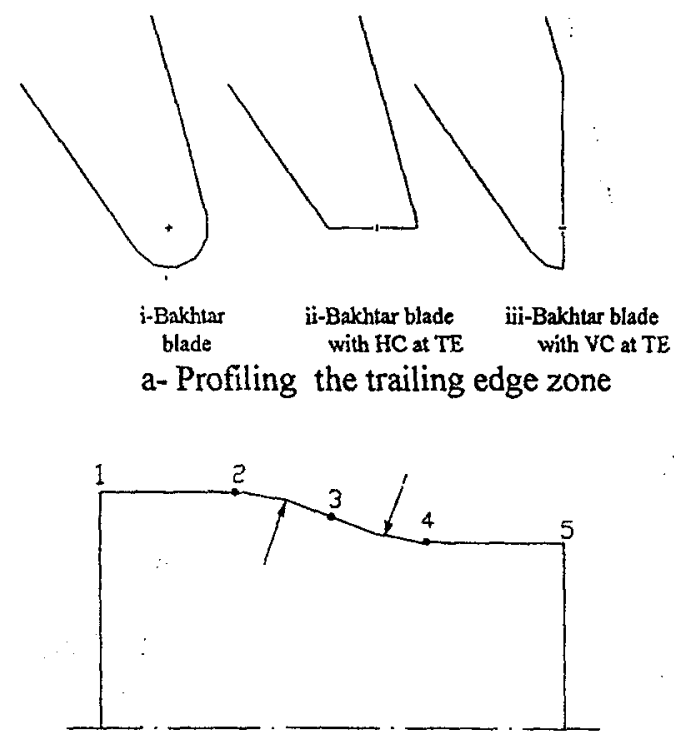

1-2: straight section, 2-3: concave arc, 3-4: convex arc and 4-5: straight section.

$$
\text { b- Profiling the blade end -wall }
$$

Figure (2): Configurations of blade profiling 


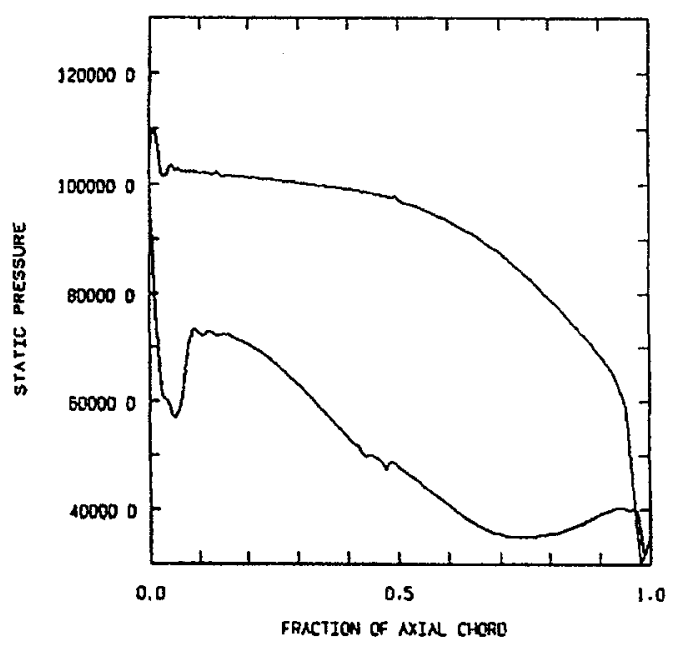

i- Static pressure surface distributions

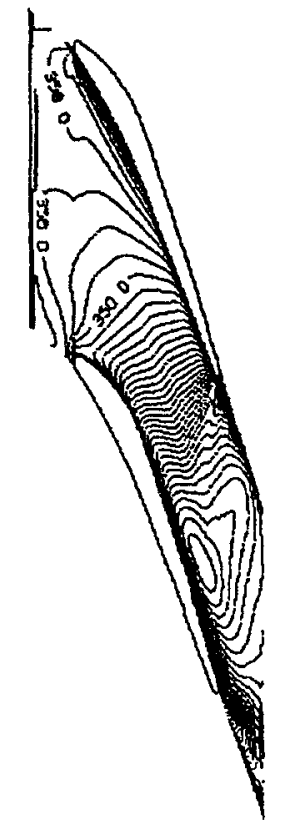

iii- static temperature contours

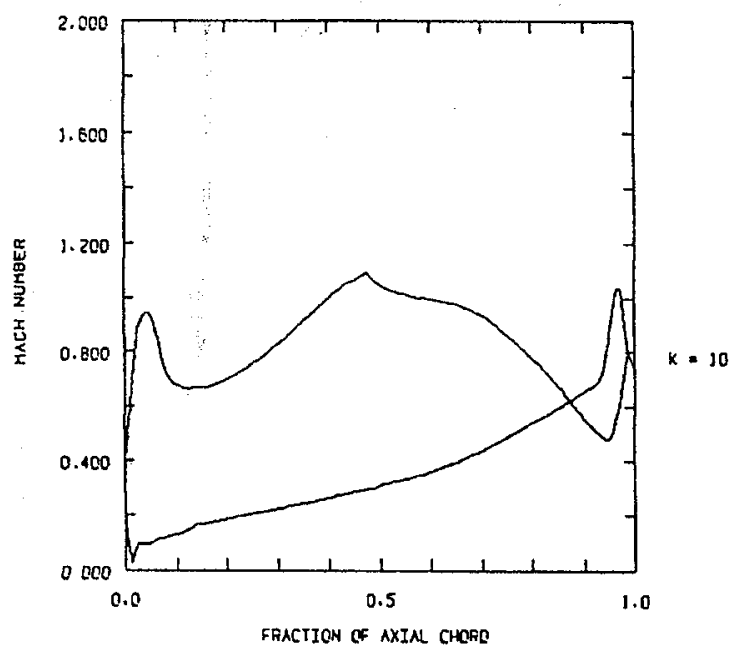

ii- Mach number surface distributions

a- Aerodynamic characteristics

Fig. (3) : Some plots from the present model predictions for flow characteristics of nucleating steam expanding through cascade blades of Bakhtar, et al [21] profile. 


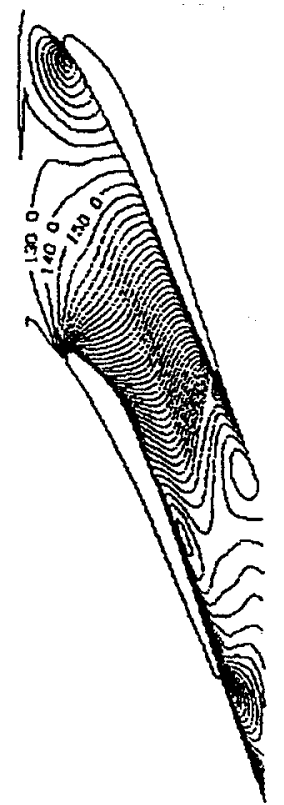

i- velocity contours

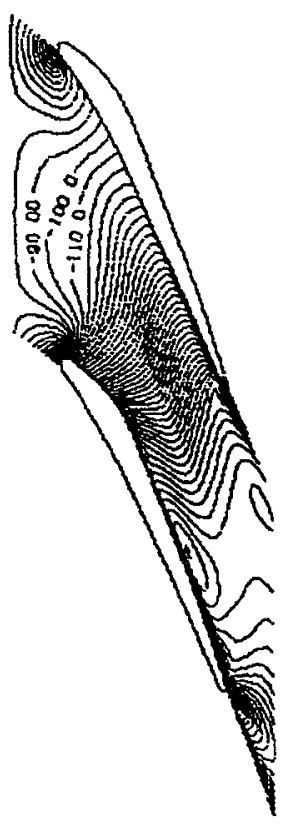

iii- tangential velocity contours

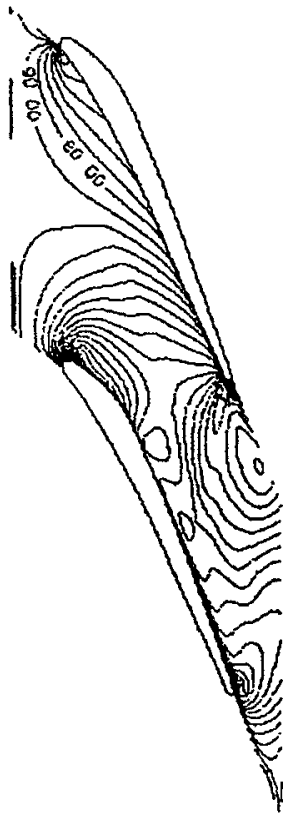

ii- axial velocity contours

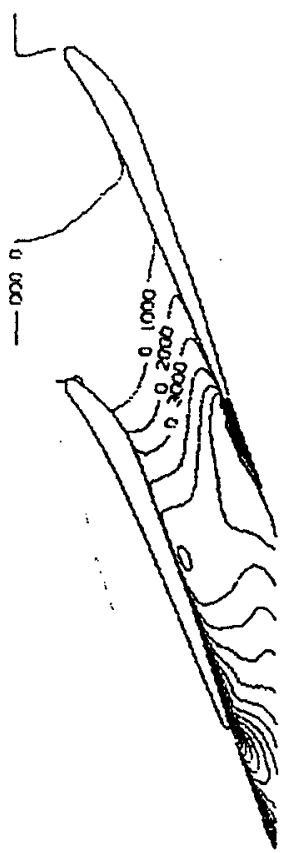

iv- radial velocity contours

b- Velocity characteristics

Fig. (3)- cont. : Some plots from the present model predictions for flow characteristics of nucleating steam expanding through cascade blades of Baktar, et al [21] profile. 


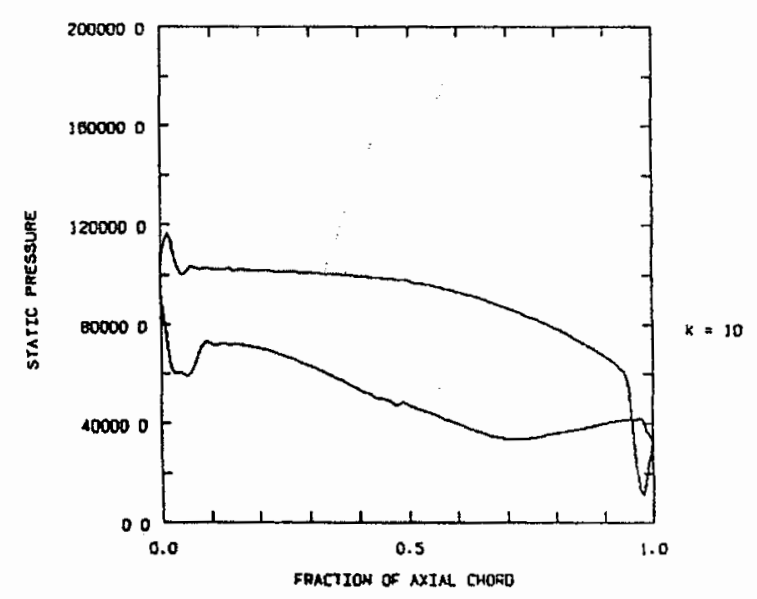

a- Surface distribution of static pressure

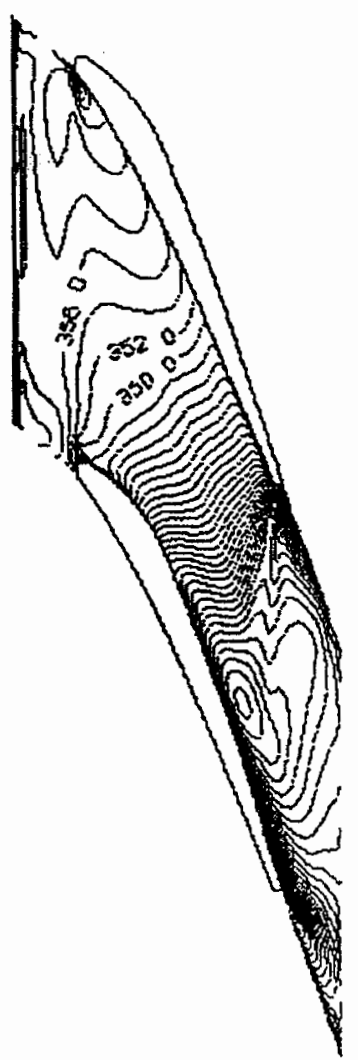

c- Static temperature contours

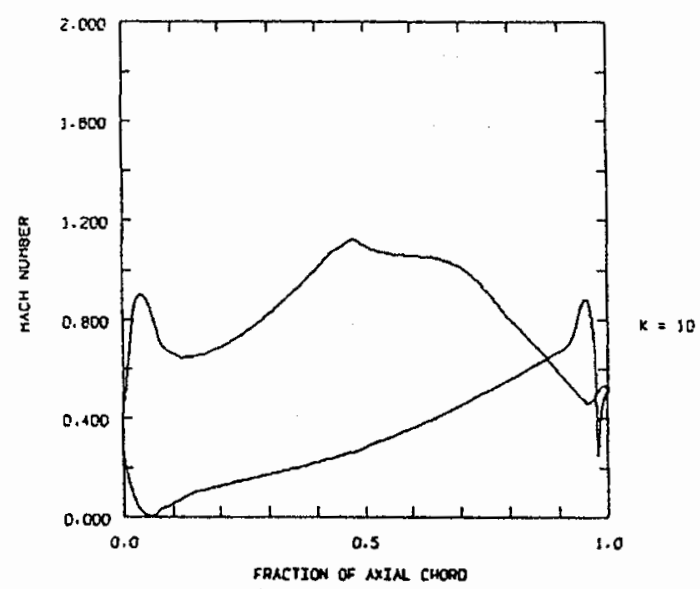

b- Surface distribution of Mach number

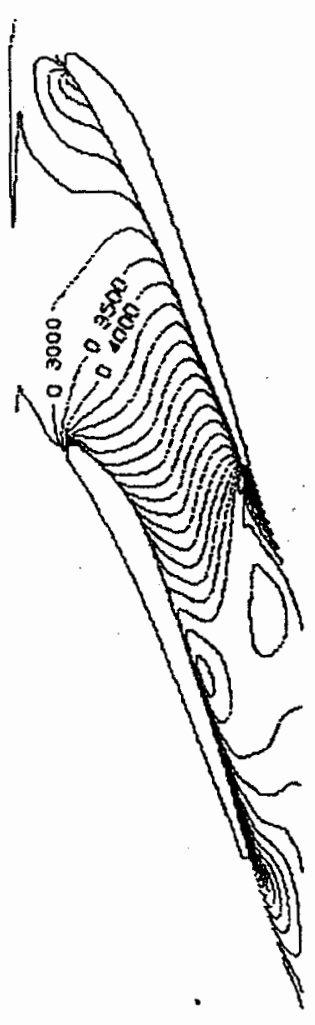

d- Mach number contours

Figure (4): A sample of present model prediction for flow characteristics of nucleating steam expanding through cascade blades of basic profile and with $\mathrm{HC}$. 


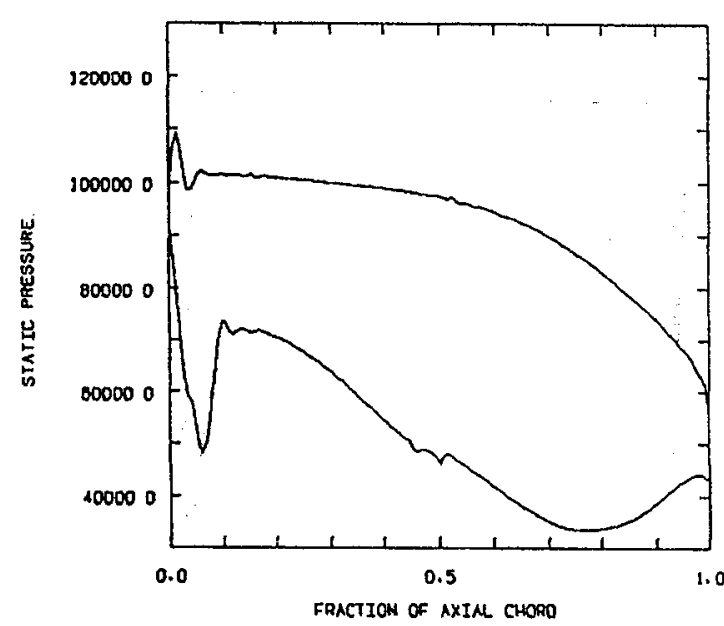

a- Surface distributions of static pressure

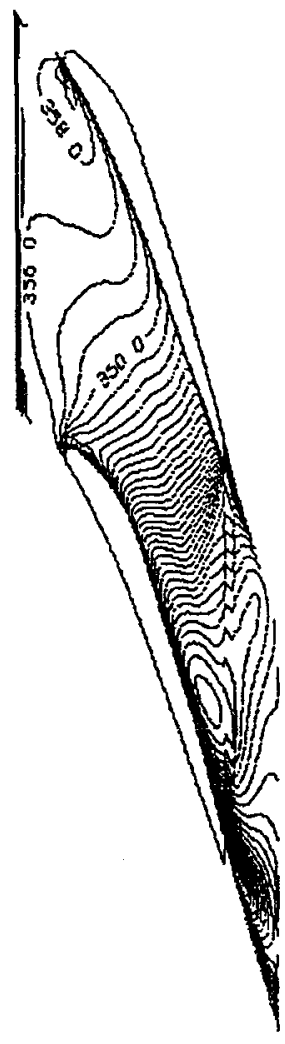

c- Static temperature contours

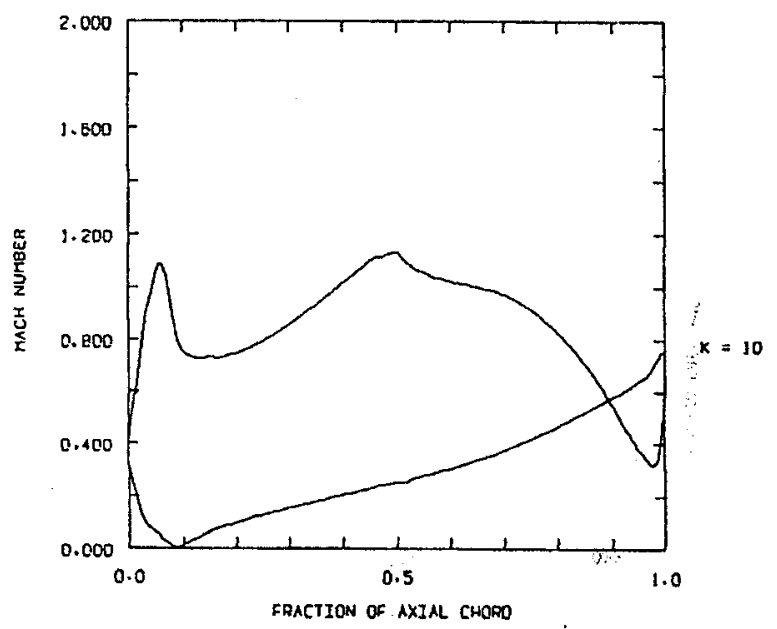

b- Surface distributions of Mach number

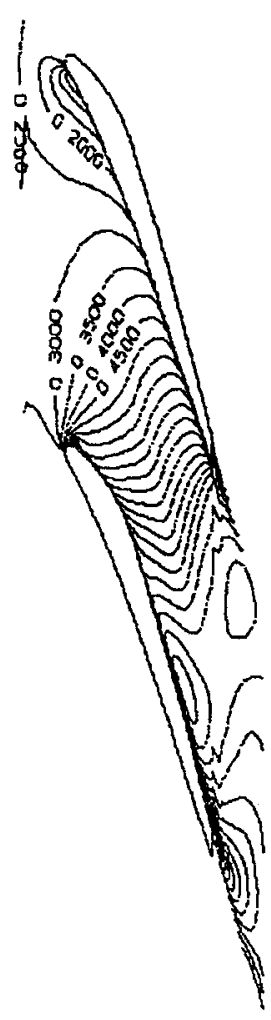

d- Mach number contours

Figure (5): A sample of present model prediction for flow characteristics of nucleating steam expanding through cascade blades of basic profile and with VC. 

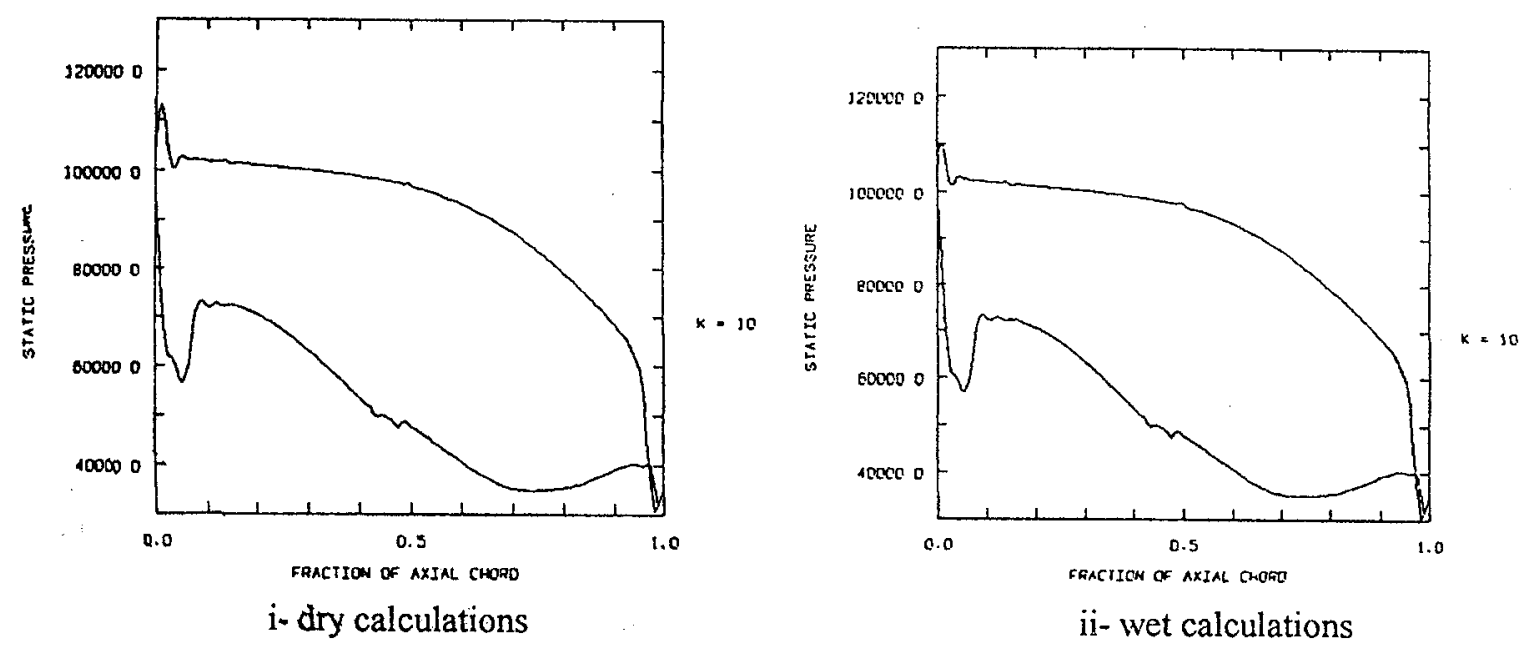

a- surface distributions of static pressure

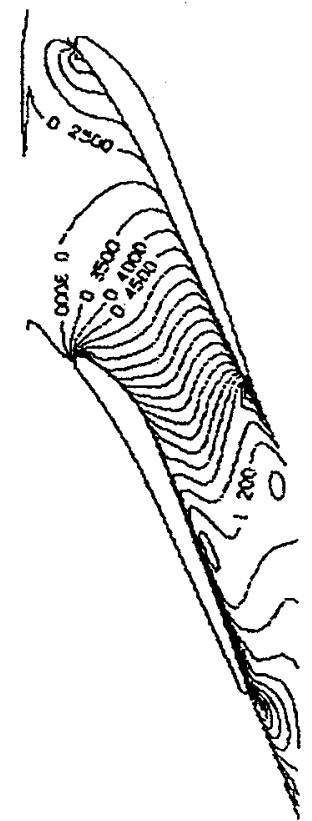

i- dry calculations

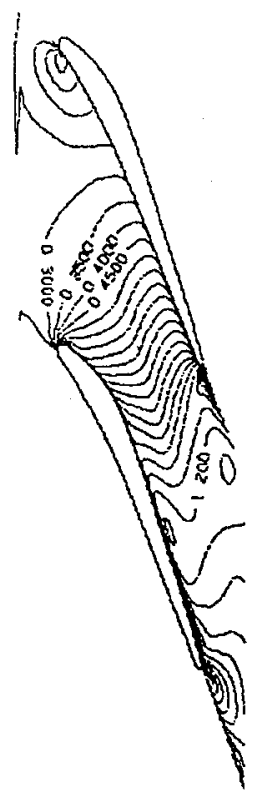

ii- wet calculations

b- Mach number contours

Fig. (6) : Effect of condensation on the predicted static pressure distributions upon blade surfaces and Mach number contours for steam flow through cascade blades of Bakhtar, et al [21] profile. 

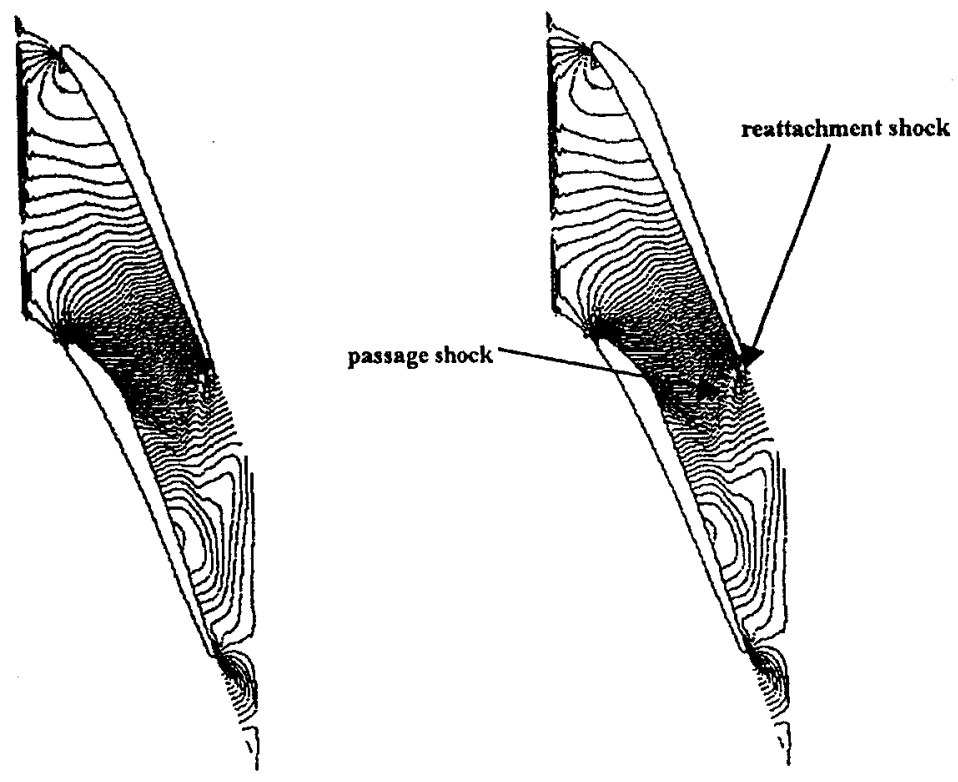

a- static pressure contours
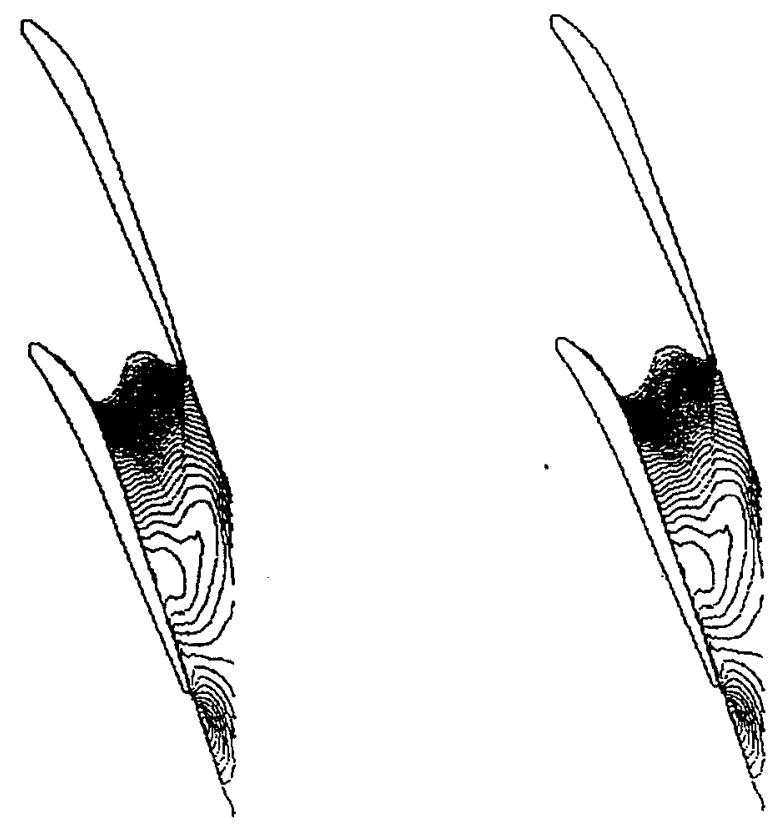

b- wetness fraction contours

i- blades with $\mathrm{HC}$ ii- basic blades

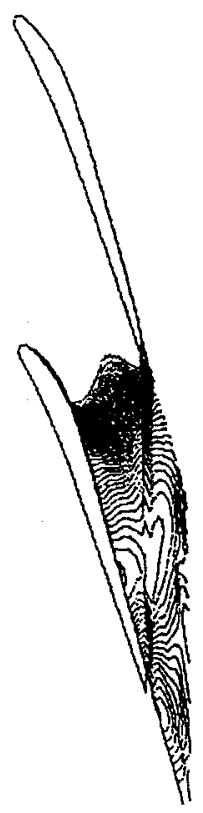

iii- blades with VC

Figure (7) : Effect of TE zone profiling on the predicted static pressure and wetness contours 


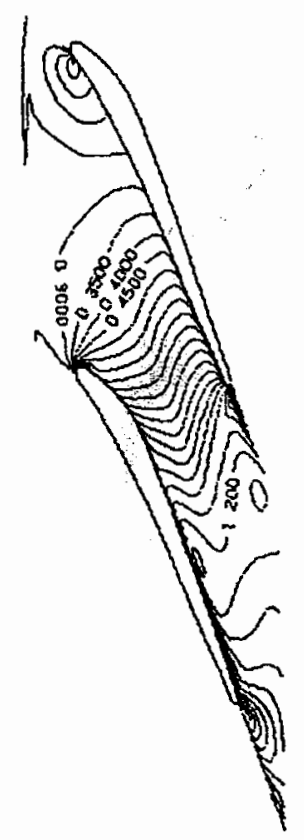

a- Mach number contours
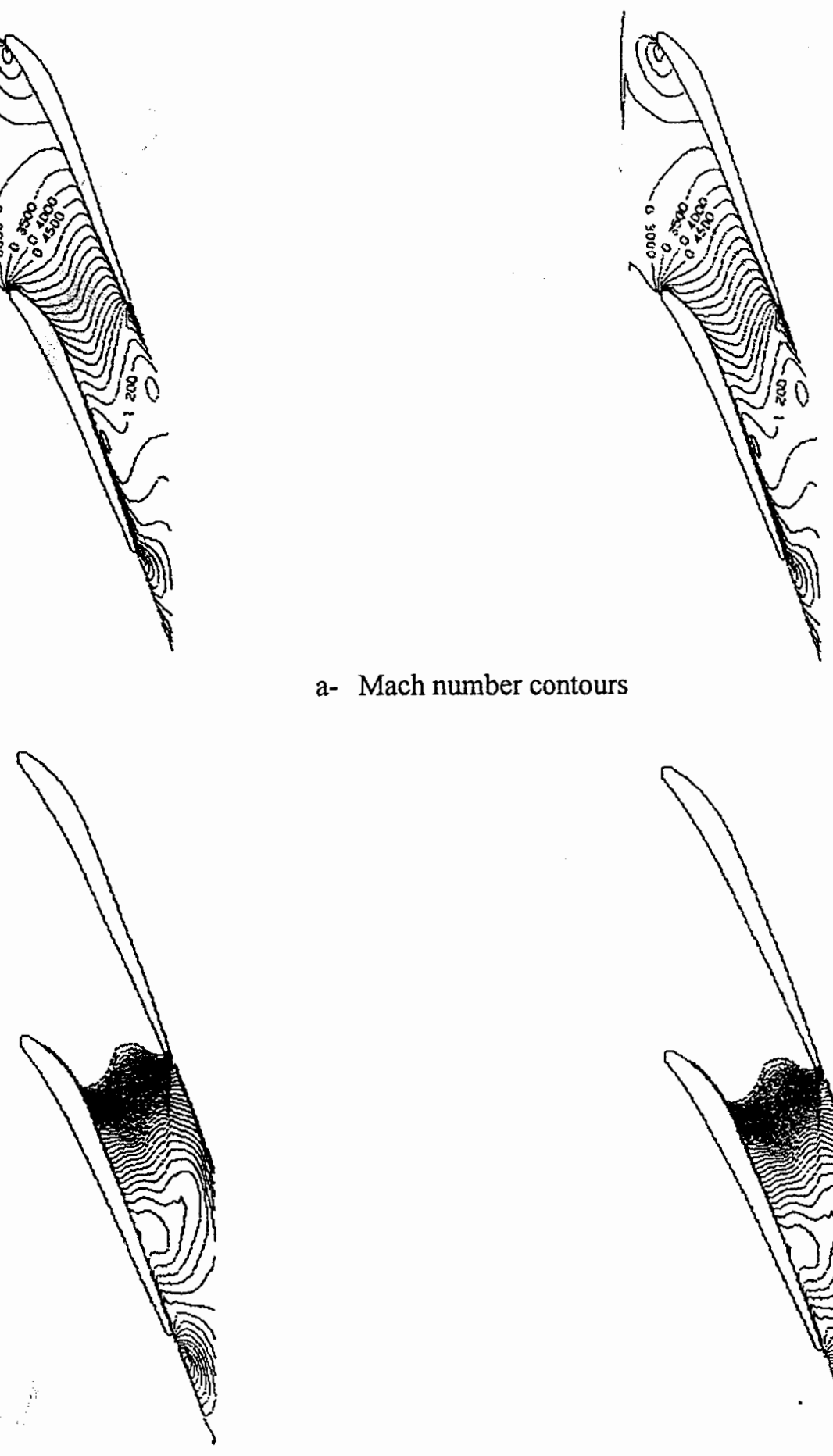

b- Wetness fraction contours

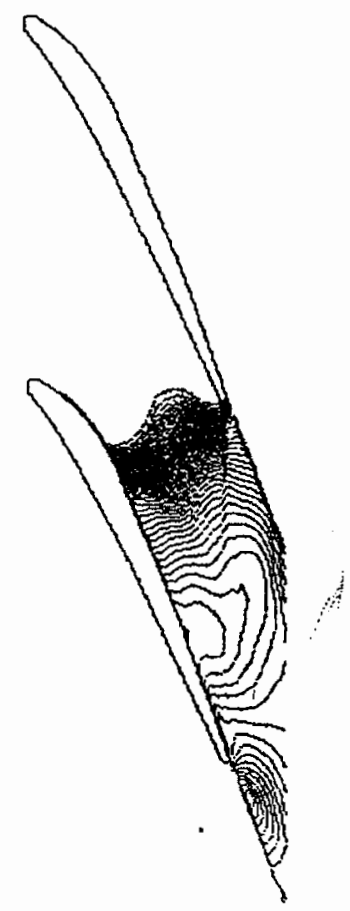

1-Blades without EW profiling

2- Blades with EW profiling

i- Aerodynamic characteristics

Figure (8) : Effect of EW profiling on some of model predictions for nucleating steam flow through a tested cascade contains blades of Bakhtar, et al [21] profile. 

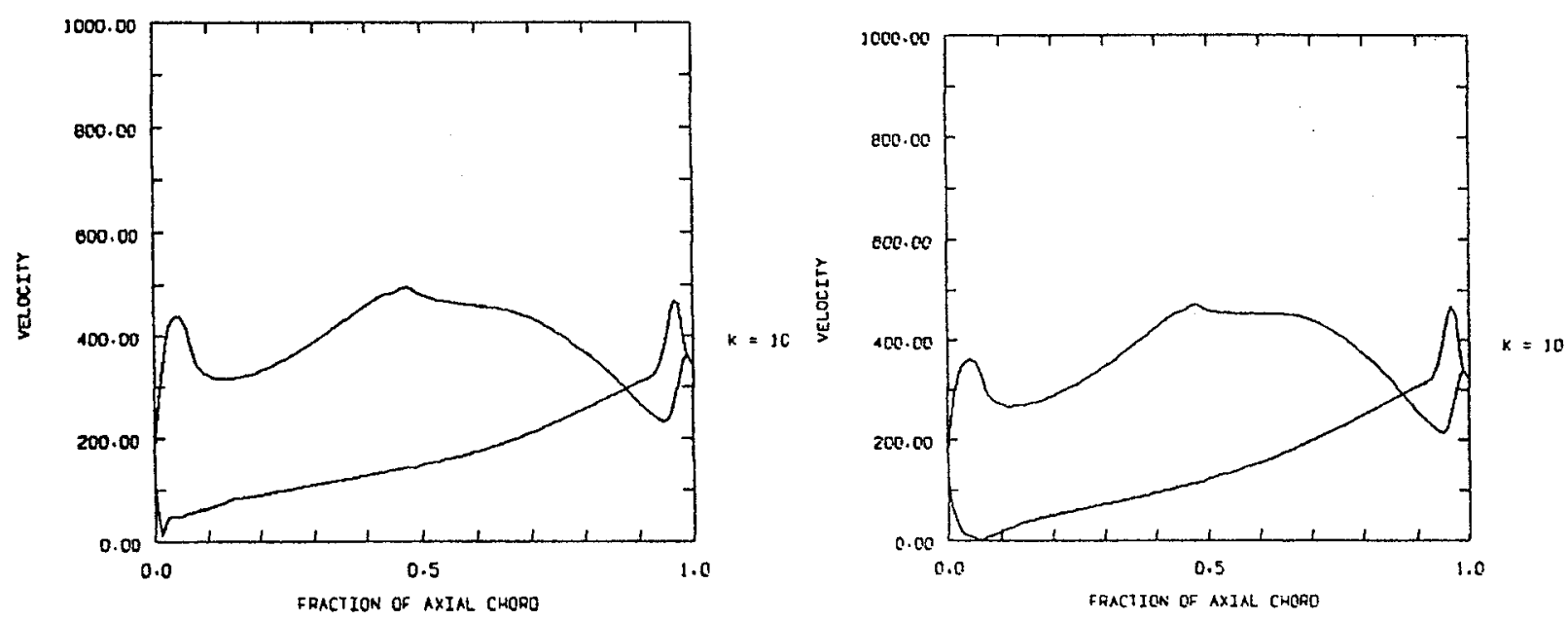

c- Surface distributions of mean velocity
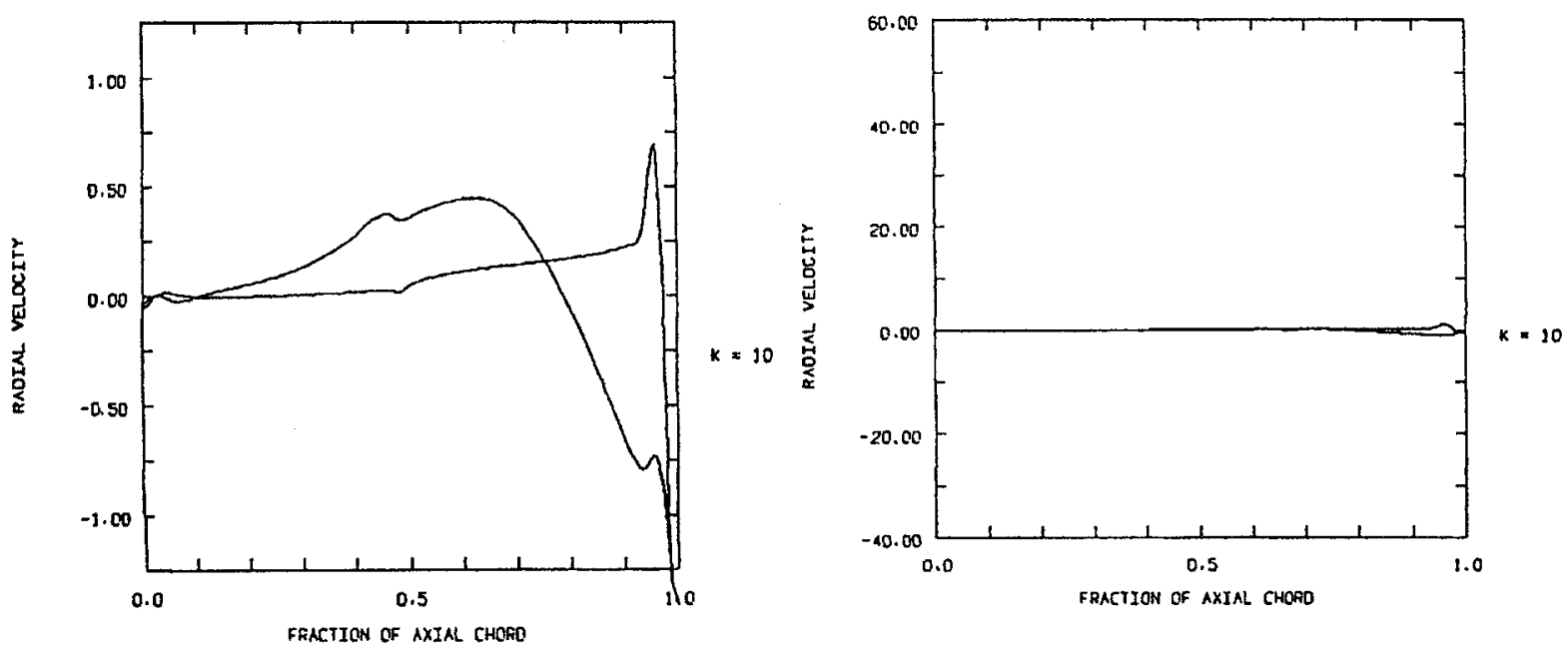

d- Surface distributions of radial velocity

1- blades without $\mathrm{EW}$ profiling

2- blades with EW profiling

\section{ii- Velocity characteristics}

Figure (8) cont. : Effect of EW profiling on some of model predictions for nucleating steam flow through a tested cascade contains blades of Bakhtar, et al [21] profile. 

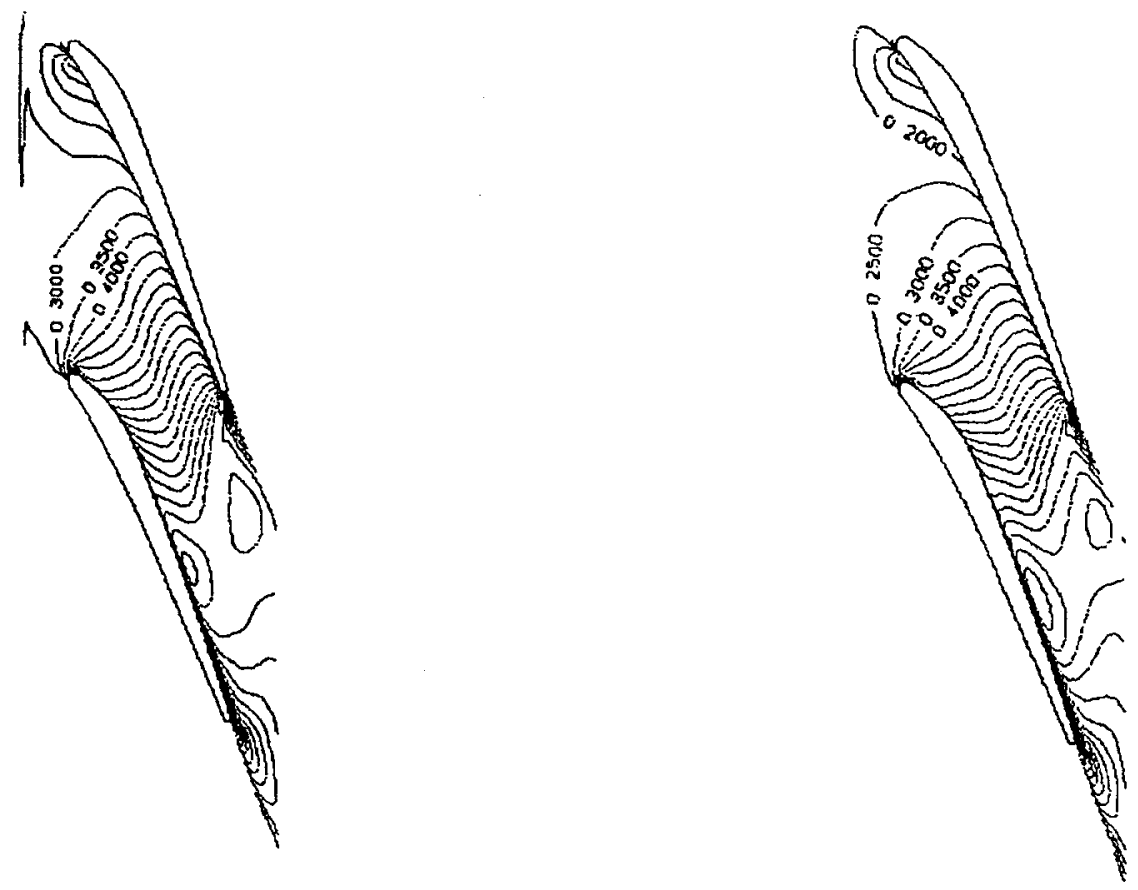

a- Mach number contours
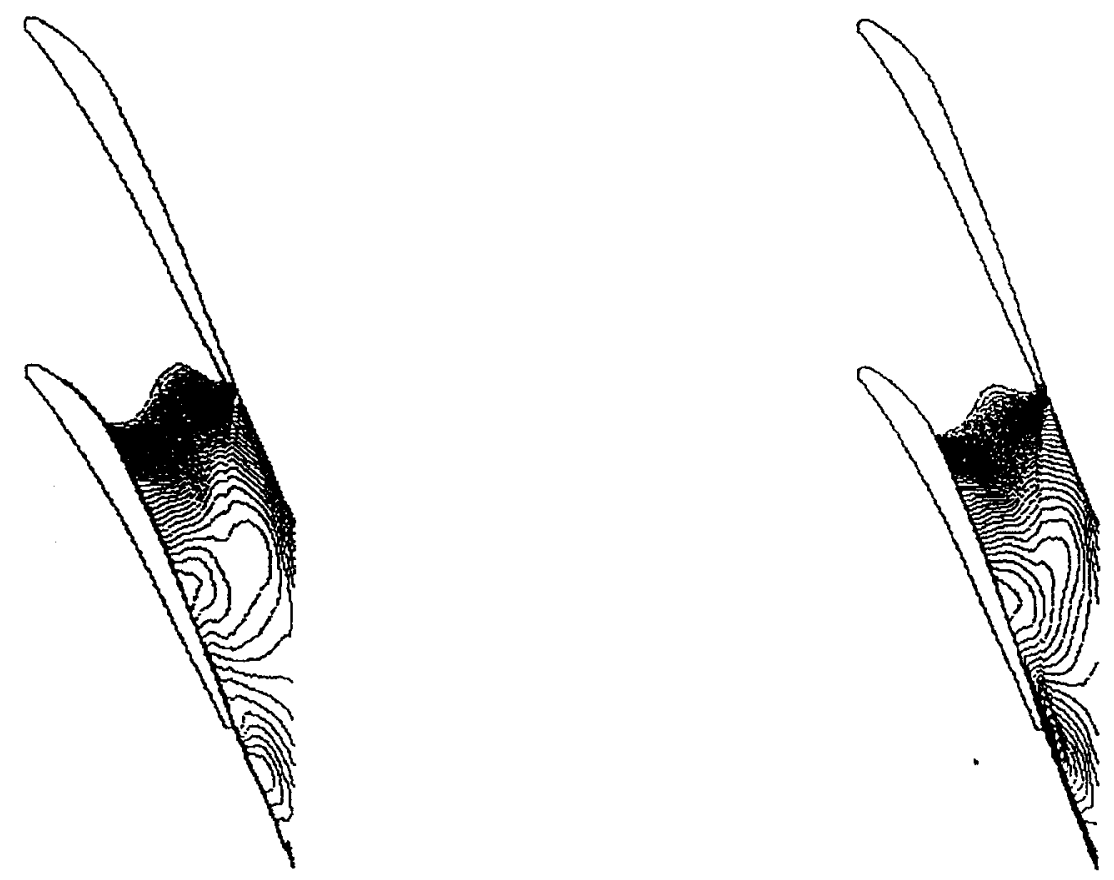

1- blades without EW profiling

2- blades with EW profiling

b- Wetness fraction contours i- Aerodynamic characteristics

Figure (9) : Effect of EW profiling on some of model predictions for nucleating steam flow through a tested cascade contains blades of Bakhtar, et al [21] profile and $\mathrm{HC}$. 

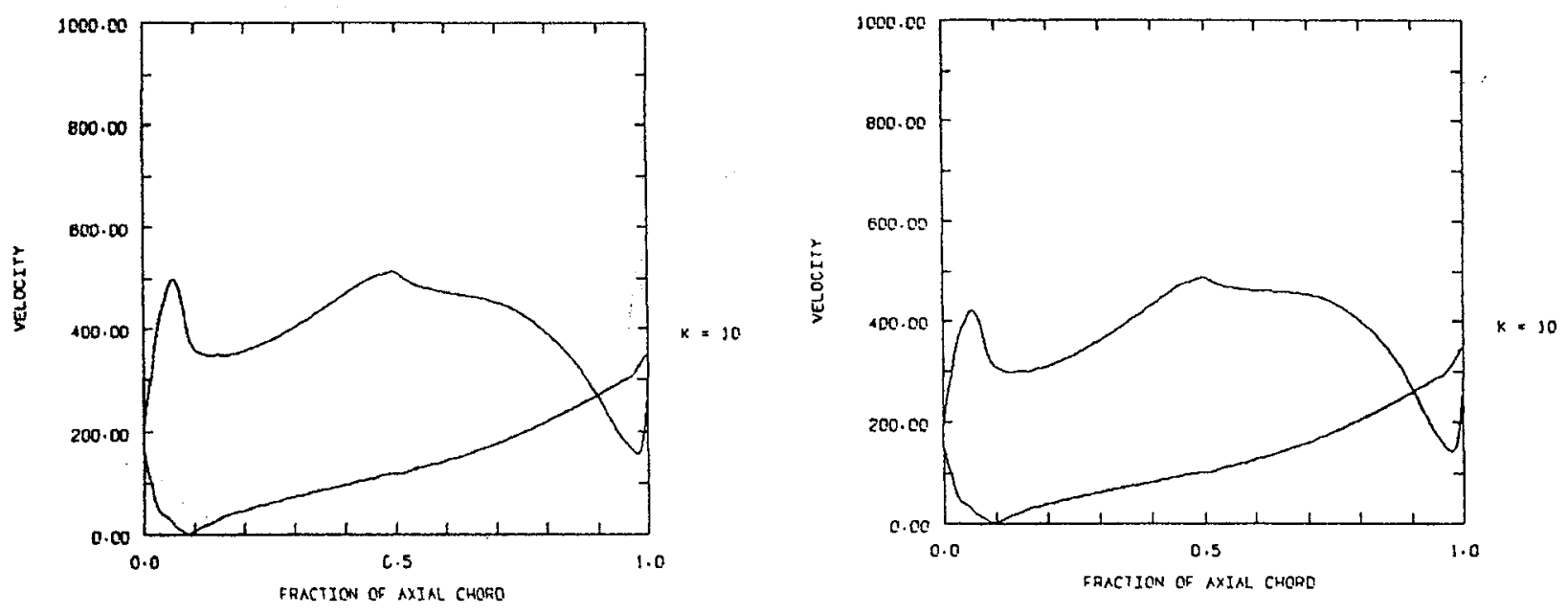

c- Surface distributions of mean velocity
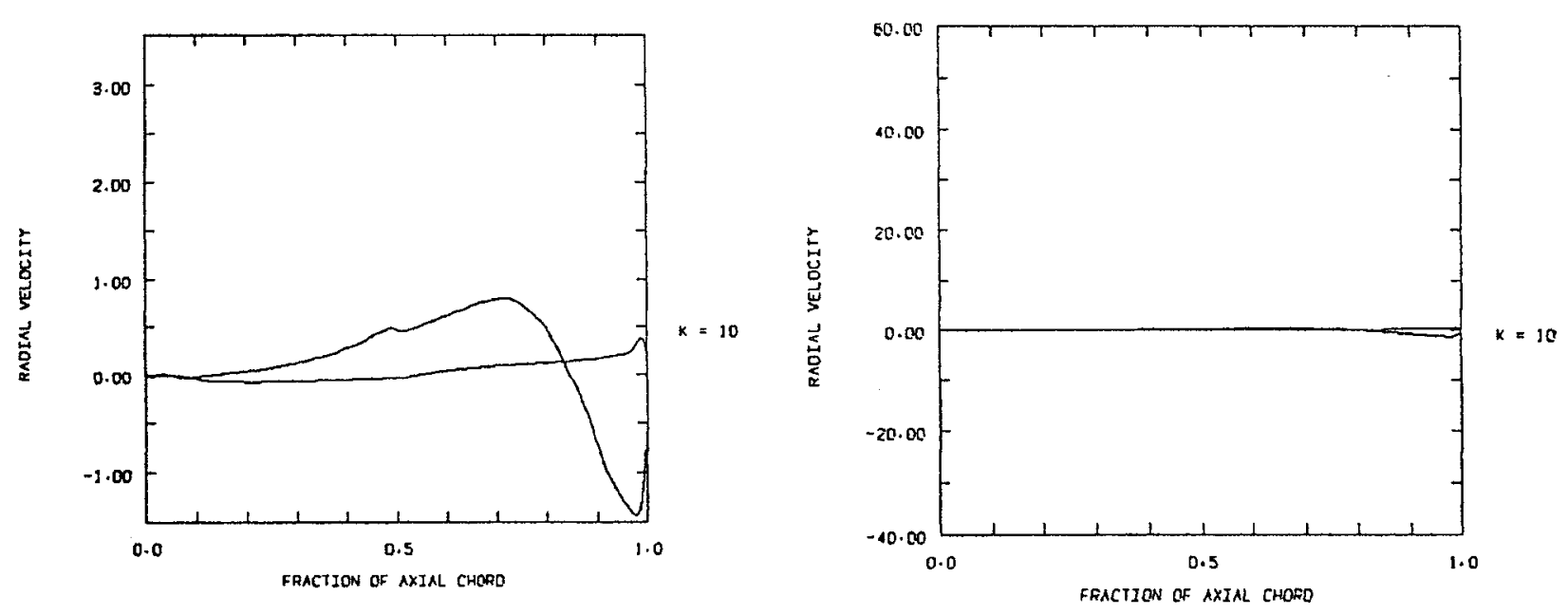

\section{d- Surface distributions of radial velocity}

1- blades without EW

2- blades with $\mathrm{EW}$

ii- velocity characteristics

Figure (9)-cont. : Effect of EW profiling on some of model predictions for nucleating steam flow through a tested cascade contains blades of Bakhtar, et al [21] profile and $\mathrm{HC}$. 

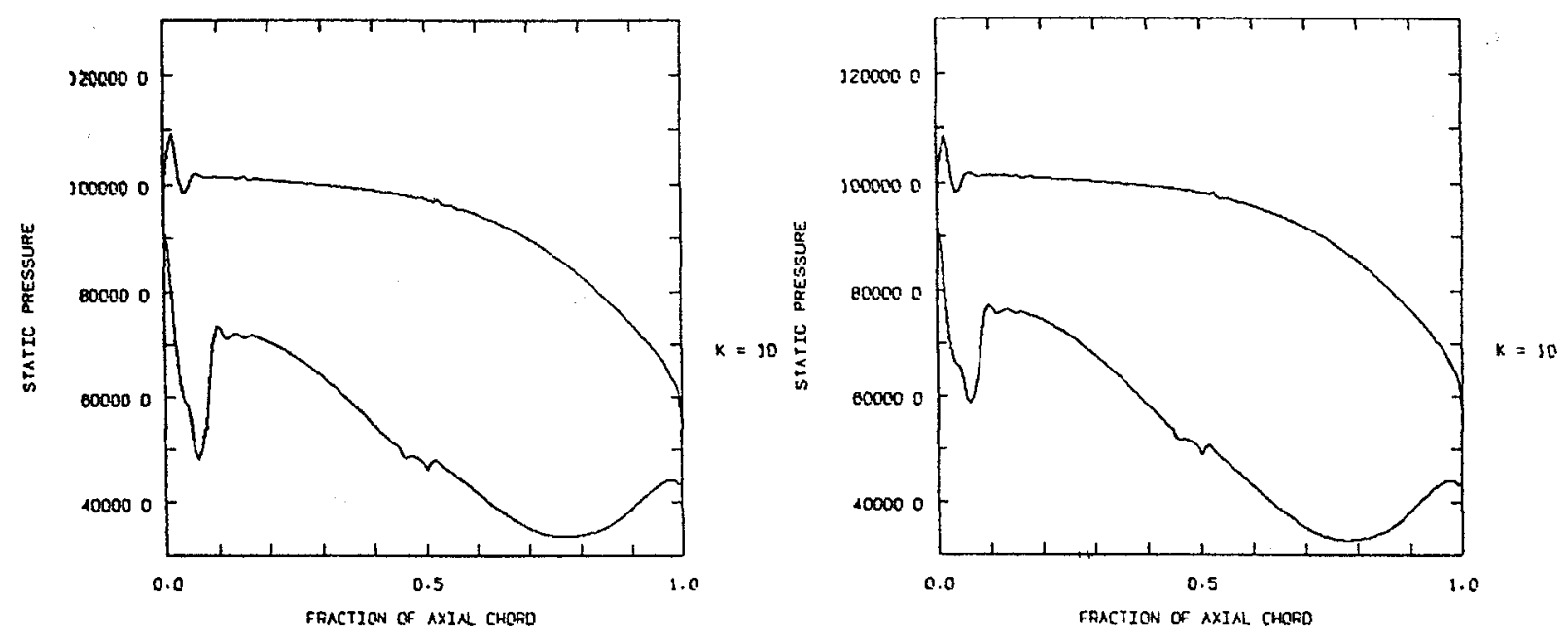

a- Surface distributions of static pressure
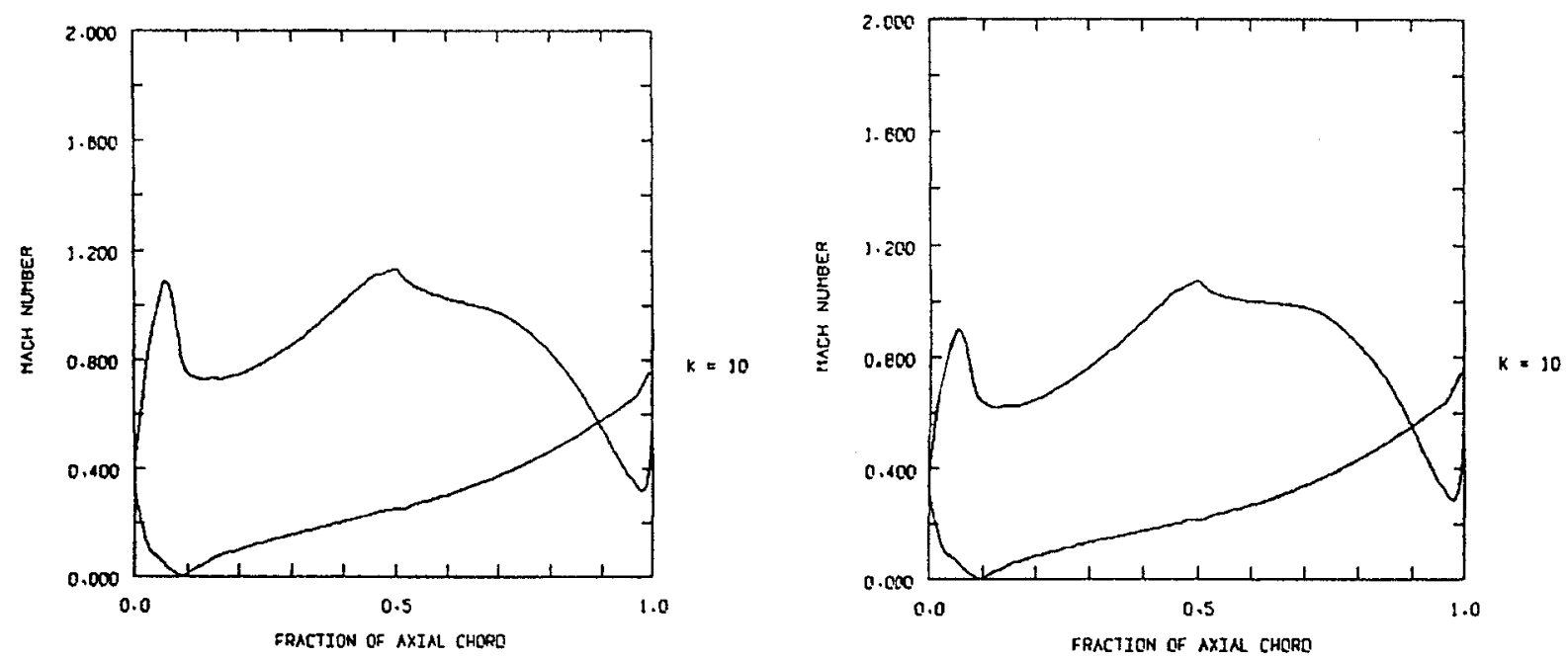

b- Surface distributions of Mach number

i- blades without EW

ii- blades with EW

Fig. (10) : Effect of EW profiling on some of present model predictions for nucleating steam flow through a cascade contains blades of Bahktar, et. al. [21] profile and with VC. 

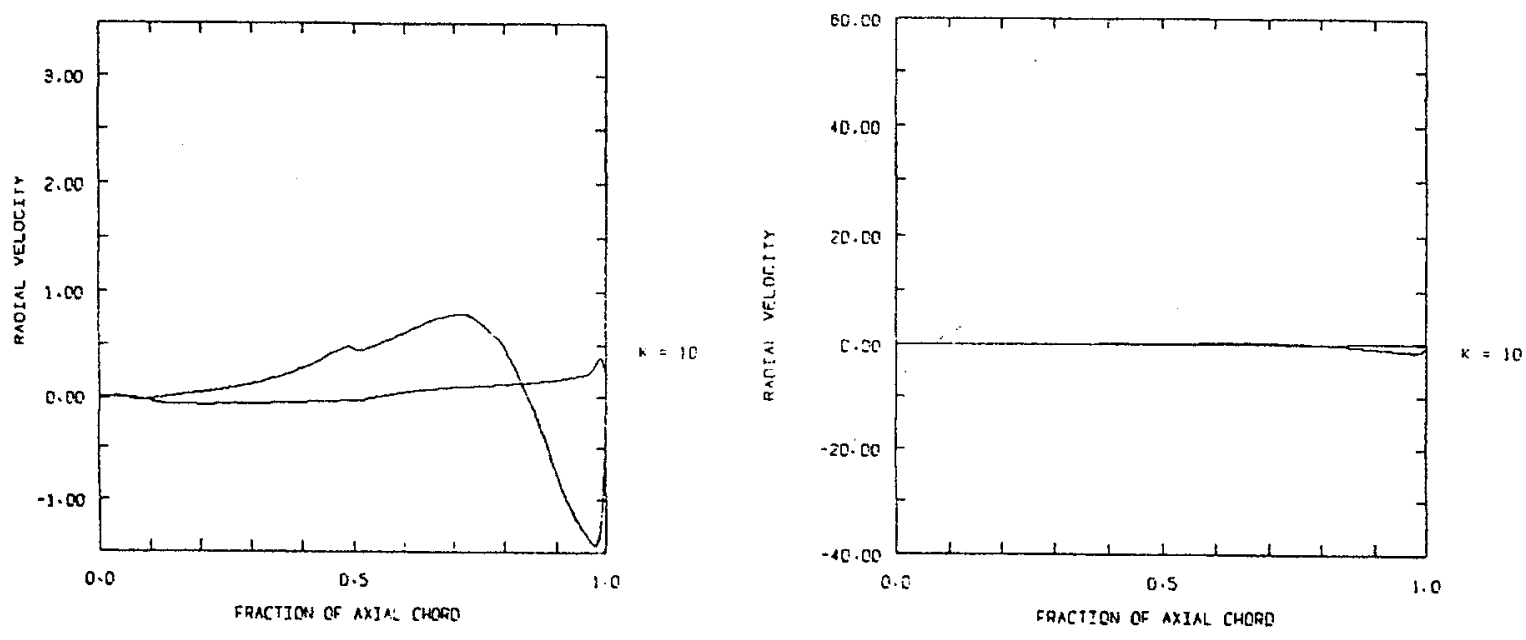

c- Surface distributions of radial velocity

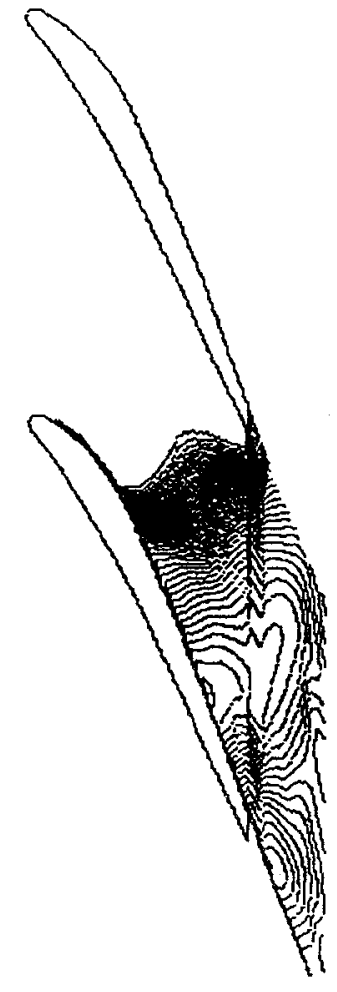

d- Wetness fraction contours

i- blades without $\mathrm{EW}$

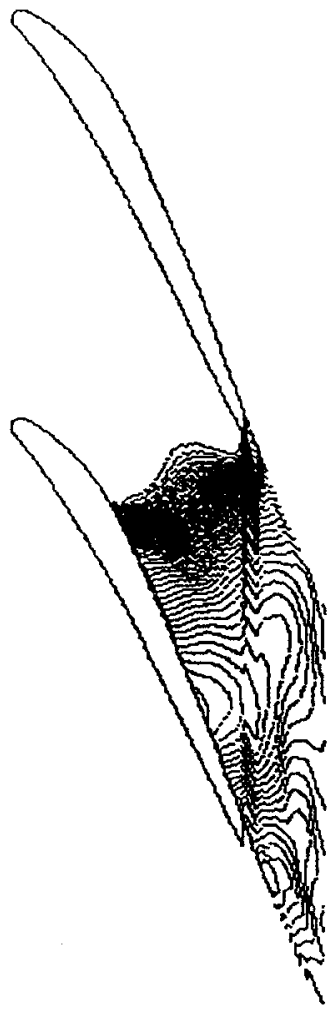

ii- blades with EW

Fig. (10)-cont. : Effect of EW profiling on some of present model predictions for nucleating steam flow through a cascade contains blades of Bahktar, et. al. [21] profile and with VC. 


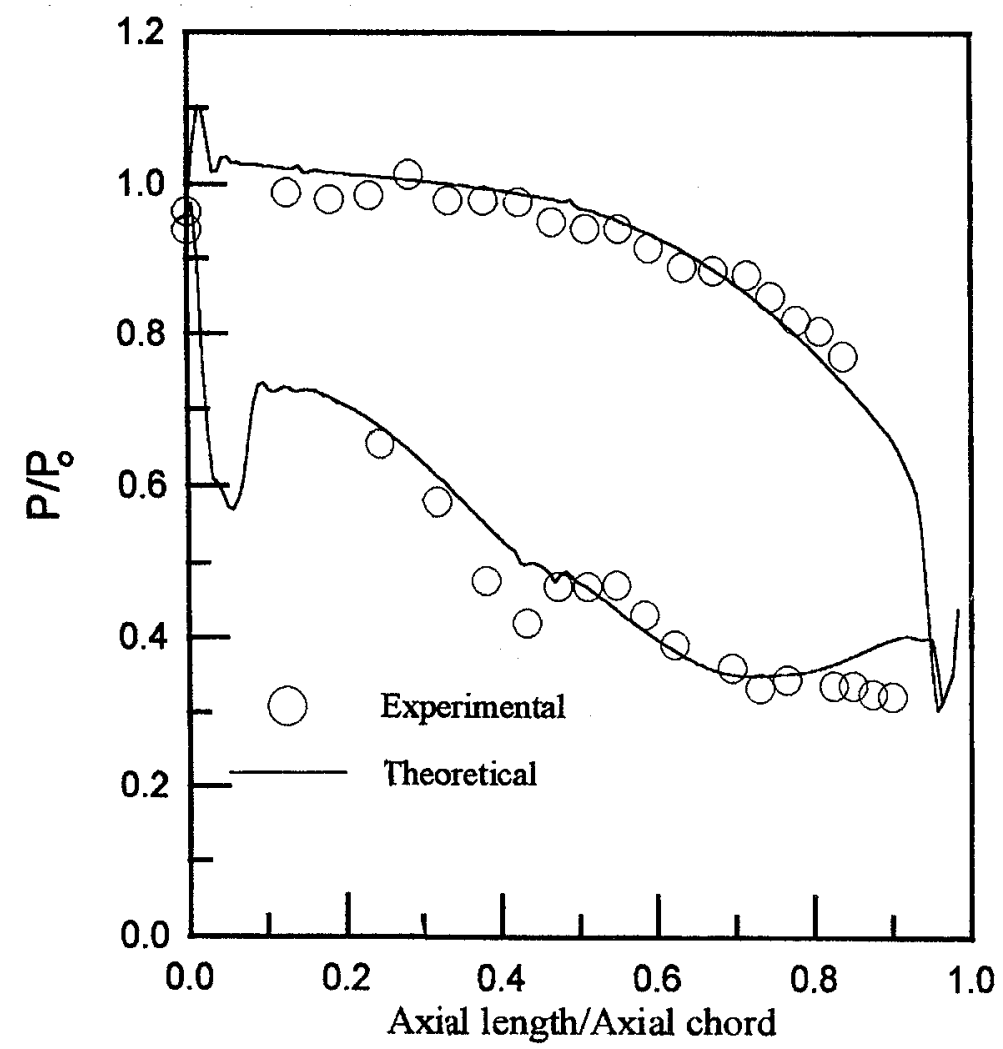

Figure (11) A comparison between present predictions and experimental results of Bakhtar et al [21].

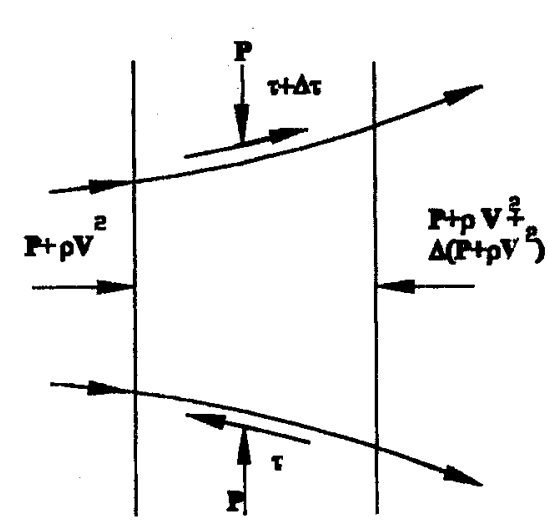

a- Momentum fluxes

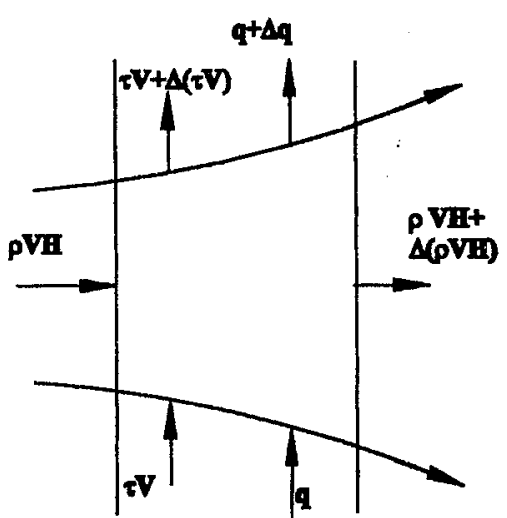

b- Energy fluxes

Figure (12): Conservation of momentum and energy through a fixed control volume 


\title{
ضبط الرطوبة والمفاقيد باستخدام إعتبارات هندسية في مراحل الضغط المنخفض من توربينات البخار
}

\author{
نبيل حنفي محمود* و أوداى سنج

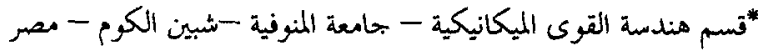

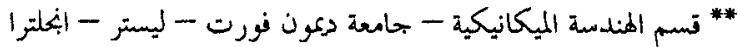

ملخص البحث

يهتم هذا البحث بفحص تأثيرات بعض الخصائص المندسية لمصفوفة ريش مر احل الضغط المنخفض في

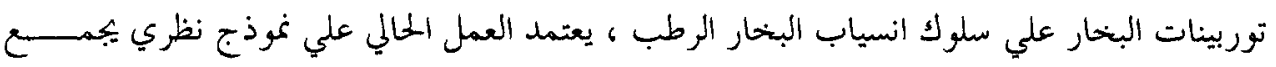

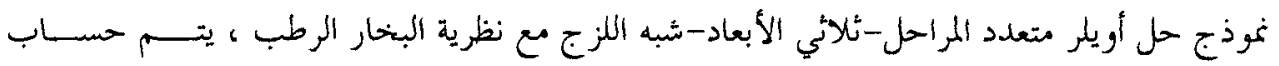

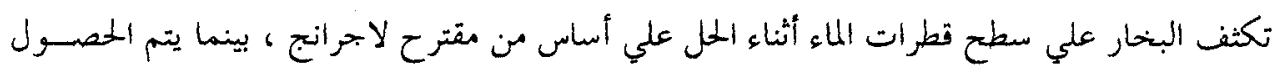

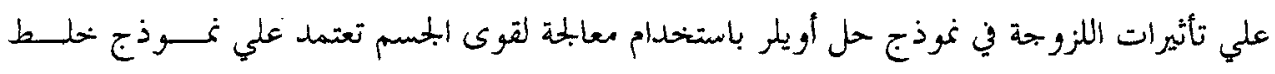

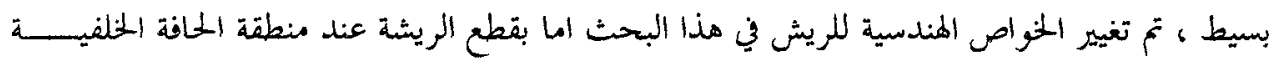

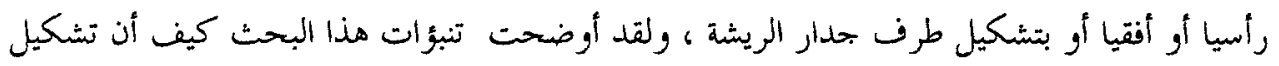

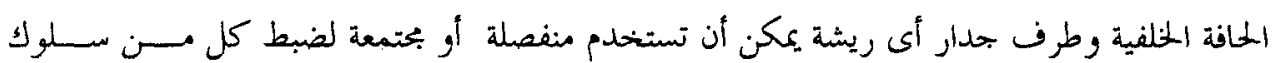

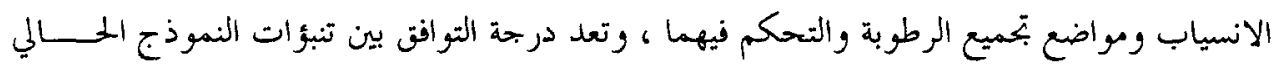

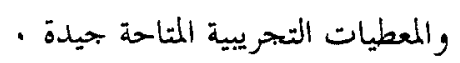

